\title{
LOS HOMBRES DE NEGOCIOS EN LA CIUDAD DE SORIA DURANTE EL SIGLO XVI.
}

por

\author{
MÁximo DIAGo HERNANDo \\ Instituto de Historia. \\ C.S.IC. Madrid.
}

RESUMEN: En una línea de investigación orientada a profundizar en el conocimiento de la estructura socioeconómica de las ciudades castellanas en el siglo XVI, el presente artículo se centra en la caracterizacion del grupo sacial dedicado a los negocios mercantiles y financieros en esta época en Soria, ciudad de tamaño medio y punto central de una extensa región donde se producia gran cantidad de lana de ganado trasbumante destinada a la exportación. Se presta particular atención a la identificacion de los mercaderes sorianos que participaron en empresas de exportación de lana a Italia, Francia y Flandes. Y luego se analizan otras vías de participación en el negocio mercantil hanero abiertas a ertos mercaderes. Se demuestra que mucbos de ellos fueron también propietarios de rebaños trasbumantes, $y$ que además se dedicaron a otras muy diversas actividades económicas, entre ellas la fabricación de paños. Finalmente, para situarlos mejor en la jerarquía sociopolítica de la Soria del momento, se aportan datos sobre su grado de riqueza y compasición de sus patrimonios.

Palabras Clave; Castilla. Soria. Siglo XVI. Mercaderes. Comercio lanero. Trashumancia.

\footnotetext{
SIGLAS UTILIZADAS:

AHPS, PN:

Archivo Histórico Provincial de Soria. Protocolos Notariales. A continuación siempre indicamos, en este orden, el número de caja, número de expediente, y, cuando están foliados, número de folio.

AChV, P.C.: Archivo de la Chancillería de Valladolid. Pleitos Civiles. A continuación el nombre de la escribanía.

F.: Fenecidos. A continuación el número de caja, y después número de expediente.

AHN, OOMM: Archivo Histórico Nacional. Ordenes Militares.
} 
ABSTRACT: To improve our knowledge of the social and economic structure of Castilian towns in the sixteenth century, this article tries to characterize the social group dedicated to trade and business in Soria, a middle-sized Castilian town situated in a region where a lot of wool was produced for export. Special attention is paid to the identification of Sorian merchants active in the export of wool to Italy, France and Flanders. Then it analyzes otber ways of profiting from the wool trade that were open to these merchants. Many of them were also owners of sbeep flocks, and invested in many other economic activities, among them cloth-making. Finally, in order to situate these merchants in the urban bierarchy, some information is given about their economic wealth, and it is proved that they were much less rich than the members of the noble oligarchy.

KEY wORDS: Castile. Soria. Merchants. Wool trade. Trashumance.

Para profundizar en la caracterización desde el punto de vista socioeconómico de un núcleo urbano resulta indispensable identificar al grupo social que en el mismo asumió el desempeño de las principales actividades mercantiles y financieras, y dar cuenta de la posición que se le asignó en la jerarquía sociopolítica urbana en relación con el resto de los grupos sociales de la ciudad. Los análisis de historia social urbana enfocados desde la perspectiva comparativa aplicada al conjunto de la Europa occidental en época bajomedieval y moderna nos permiten descubrir a este respecto un panorama excepcionalmente diversificado y rico en matices, determinado por un sinfín de variables. Pero no por ello estamos condenados a tener que contentarnos con la descripción y contrastación de múltiples singularidades, sino que el análisis comparado también permite entrever tendencias y esbozar tipologías, que contribuyen a explicarnos mejor los contrastes que en la evolución histórica se constatan entre unas y otras ciudades, y también entre unos y otros ámbitos políticos y de civilización.

A este respecto, en algunos de nuestros trabajos anteriores hemos tenido ocasión de llamar la atención sobre los múltiples contrastes que en la forma de organización política, social e incluso jurisdiccional, se advierten de forma progresivamente acentuada durante los siglos bajomedievales entre el conjunto de las ciudades castellanas y las de otros ámbitos europeos, particularmente el alemán, que es el que hasta ahora hemos tenido ocasión de analizar más en profundidad ${ }^{1}$. De entre las conclusiones obtenidas en estos trabajos una de las que más nos interesa tomar en consideración en el presente contexto es la constatación de la ausencia de un auténtico patriciado en las ciudades castellanas, fenómeno que guarda estrecha relación con el de la generalizada postergación sociopolítica en estas ciudades de los sectores sociales más volcados hacia las

1 Vid. nuestros artículos «El perfil socioeconómico de los grupos gobernantes en las ciudades bajomedievales: análisis comparacivo de los ejemplos castellano y alemán» En la España Medieval, 18 (1995), pp. 85-134. Y «Las ciudades medievales en Castilla y en el Imperio alemán. Análisis comparativo de su perfil jurídico" $A H D E,(1995)$, pp. 1037-1070. 
actividades financieras y mercantiles, a los que convencionalmente identificamos como el grupo de los hombres de negocios, o, en otra terminología, de la burguesía mercantil.

La definición de las categorías «hombres de negocios» o «burguesía mercantil» resulta sumamente problemática, porque pueden entenderse en un sentido más o menos restringido, pero preferimos utilizarlas en lugar de la de «burguesía» por motivos ya indicados en los artículos anteriormente citados. La peculiar evolución sociopolítica del reino de Castilla desde los siglos bajomedievales impidió que este grupo social alcanzase definición y coherencia tanto en las ciudades como en el conjunto del reino, y esta circunstancia queda reflejada en el hecho de que ni en la Castilla bajomedieval ni en la moderna podemos encontrar formas de organización corporativa de estos hombres de negocios semejantes a las de sus socios ingleses, que tomaton cuerpo sobre todo a partir del reinado de Eduardo III $^{2}$.

En el marco concreto de las distintas ciudades castellanas en particular la organización estamental que terminó consolidándose en la mayoría de ellas tampoco aseguró a este grupo un lugar bien definido en la jerarquía sociopolítica urbana, a diferencia de las ciudades de la Corona de Aragón, de las que Barcelona nos ofrece un ejemplo paradigmático ${ }^{3}$. En la mayor parte de las ciudades castellanas se consolidó en los siglos bajomedievales entre la población

2 En la Inglaterra de la primera mitad del XIV fue frecuente que el rey convocase asambleas de mercaderes, para tratar asuntos que les incurnbian, y a partir de 1376 los Comunes asumieron el papel de representantes de los intereses de los mercaderes del reino. Vid. W.M. ORMROD, The reign of Edward III. Crown and Political Society in England 1327-1377, New Haven-Londres, 1980, pp. 186 y ss. Sobre el proceso de aparición y consolidación de la corporación de mercaderes (merchant class) en Inglaterra vid. MILLER, E. y HATCHER, J.: Medieval England. Touns, Commerce and Crafts. 1086-1348, Londres-Nueva York, 1995, pp. 225 y ss. En Castilla la representación de las ciudades en Cortes nunca tuvo el carácter de instrumento de representación corporativa de los hombres de negocios y mercaderes. En este sentido entendemos que la categoría de patriciado que maneja el profesor Ruiz Martín en sus trabajos sobre las Cortes castellanas en los siglos XVI y XVII puede dar lugar a equívocos, pues no da cuenta del hecho de que la mayoría de los representantes a Cortes de las ciudades castellanas de esta época eran miembros de la nobleza, que nada tenían que ver con lo que convencionalmente entendemos como hombres de negocios. Vid. RUIz MARTIN, F.: «La Hacienda y los grupos de presión en el siglo XVII" en Estado, Hacienda y Sociedad en la Historia de España, Valladolid, 1989, pp. 97-122.

3 En Barcelona el estamento de los «ciutadans honrars» respondia al arquecipo de estamento burgués y patricio, perfectamente diferenciado del estamento noble rutal, y se nutría principalmente de hombres de negocios entiquecidos cada vez más inclinados a la vida rentista. Vid. GERBET, M.C.: «Patriciat et noblesse à Barcelone à l'époque de Ferdinand le Catholique. Modalités et limites d'une fusion" en Viller et societés urbaines au Moyen Age. Hommage dे M. Le Proferseur Jacquer Heers, París, 1994, pp. 133-40. Pero por debajo de él existía un estamento medio, el de los «mitjanes", que integraba a mercaderes en activo junto con un amplio espectro de profesionales de la clase media, y estaba perfectamente diferenciado del grueso de la población trabajadora, que comprendería en torno al $80 \%$ del total de la población urbana. Vid. MUTGE VIVES, J.: La ciudad de Barrelona durante el reinado de Alfonso el Benigno (1327-1336), Barcelona, 1987, pp. 97 y ss.

Hispania, LX/2, nim. 205 (2000) 479-514 
laica un modelo de organización estamental dual, que básicamente sólo diferenciaba entre hidalgos y pecheros. Y como consecuencia los hombres de negocios y mercaderes no llegaron a conformar un grupo diferenciado desde el punto de vista estamental, en contraste con otras ciudades peninsulares y europeas, en las que se conoció la existencia del patriciado como estamento.

Esta afirmación generalizadora hay que matizarla, no obstante, haciendo constar la existencia de algunos casos excepcionales como por ejemplo Almagro, donde en el siglo XV la población estaba dividida en tres estamentos, los de labradores, mercaderes e hidalgos, estando integrado el estamento intermedio de los mercaderes por individuos en su mayoría de origen judeoconverso ${ }^{4}$. Otra ciudad que conoció un modelo de organización estamental semejante fue Logroños. Y por fin un tercer ejemplo, algo más complejo, nos lo proporciona la ciudad de Toledo, donde se distinguió entre regidores ciudadanos y regidores caballeros, y se consolidó un órgano de gobierno paralelo al cabildo de regidores, el cabildo de jurados, que quedó de hecho reservado para individuos pertenecientes a familias dedicadas al ejercicio del comercio ${ }^{6}$.

Lo habitual en las ciudades castellanas tardomedievales y modernas, sin embargo, fue que los hombres de negocios, mercaderes y representantes de las clases medias en general, no tuviesen una adscripción estamental única, habiéndolos tanto en el estamento hidalgo como en el pechero, y en gran número también en el grupo de exentos conformado por los escribanos y titulados universitarios de origen pechero, que gozaban de la exención fiscal a título personal'. Y esta circunstancia ha dificultado su identificación como grupo sociopolítico diferenciado en el seno de la sociedad urbana, lo cual explica la escasez de estudios monográficos dedicados al análisis de la composición de este grupo en las distintas ciudades en particular, y a dar cuenta de sus principales actividades económicas, salvando casos excepcionales de ciudades por lo demás atípicas, como por ejemplo Sevilla, o en menor medida Segovia ${ }^{8}$.

4 Vid. Solano, E.: La orden de Calatrava en el siglo XV. Los señorios castellanos de la Orden al fin de la Edad Media, Sevilla, 1978, p. 365.

5 Vid. nuestro artículo "Conflictos estamentales por el control del gobierno municipal en Logroño a fines del XV y principio del XVI", Cuadernos de Estudios Medievales y Ciencias y Técnicas Historiográficas, 17 (1992), pp. 225-225. Un panorama más confuso sobre la organización estamental logroñesa del siglo XV ofrecen DÍAZ DE DURANA, J.R.: y GARCía FernÁnDEZ, E.: Demografia y sociedad: la población de Logroño a mediados del sigho XV, Logroño, 1991.

6 Vid. ARANDA PÉREZ, F.J.: Poder municipal y oligarquias urbanas en Toledo en el siglo XVII, Universidad Complutense, Madrid, 1992, 2 vols.

7 Sobre este grupo de los exentos no nobles tratamos en La Extremadura soriana y stu ámbito a finer de la Edad Media, Universidad Complutense, Madrid, 1992, pp. 976-981.

B Sobre Sevilla hay que destacar la monografía de R. PIKE, Aristócratas y comerciantes, Barcelona, 1978. Basándose en el precedente sentado por el analista Ortiz de Zúñiga, García-BaQuero, A.: insiste en presentar un modelo tripartito de la organización social sevillana del XVI, que distingue entre nobleza, estado medio y estado inferior o de la plebe. Vid. entte otras obras en que divulga este modelo su aportación a la obra colectiva de la que es coordinador Sevilla, Fundación Mapfre,

Hispania, LX/2, núm. 205 (2000) 479-514 
Para contribuir a mejorar nuestro conocimiento de esta parcela de la historia castellana nos hemos propuesto, por consiguiente, en el presente trabajo profundizar en la caracterización de este grupo socioeconómico convencionalmente identificado como burguesía mercantil en una ciudad en concreto, hasta ahora escasamente tenida en cuenta en las obras de historia social y económica de la Corona de Castilla en el siglo XVI: Soria.

\section{LA «BURGUUESIA MERCANTIL» EN SORIA DURANTE EL SIGLO XVI}

La elección de Soria como marco para un análisis monográfico de un ejemplo concreto de «burguesía mercantil urbana» de la Castilla del siglo XVI puede parecer a primera vista extraña, ya que no son habituales las menciones a sus mercaderes en las obras generales dedicadas al comercio y a las finanzas de la época, y ello podría inducir a hacer pensar que en este núcleo urbano de importancia demográfica modesta no se consolidó un vigoroso grupo de hombres de negocios. No obstante, Soria contaba con un factor favorable para el arraigo en su seno de una dinámica comunidad de mercaderes, como era el hecho de que en su entorno geográfico se producía una de las más importantes materias primas del comercio exterior castellano de la época tardomedieval y moderna, que era la lana, y muy en particular la fina de ganado trashumante.

El análisis en profundidad del comercio lanero en el interior del reino de Castilla no ha sido acometido sin embargo hasta ahora con decisión por parte de los investigadores, y ello no ha ayudado a valorar el papel de Soria como centro mercantil, sobre todo porque su relación con el comercio exportador, que es el único que ha atraído la atención de la investigación, era en la mayor parte de los casos sólo indirecta. Presenta sin embargo un enorme interés, de cara sobre todo a explicar la evolución socioeconómica de esta ciudad en el contexto general de la

Madrid, 1992, pp. 103 y ss. Para el caso de Segovia Vid. RoDENAS ViLAR, R: Vida cotidiana y negocio en la Segovia del Siglo de Oro. El mercader Juan de Cuéllar, Junta de Castilla y León, Valladolid, 1990.

9 No existe bibliografía especializada sobre la historia de la ciudad de Soria en el siglo XVI. Referencias indirectas en la monografia de DíEZ SANZ, E.: La Tierra de Soria. Un universo camperino en la Castilla oriental del siglo XVI, Siglo XXI; Madrid, 1995. Esta obra se centra, no obstante, en el análisis del ámbito rural sometido jurisdiccionalmenre a la ciudad. Para la época bajomedieval hemos abordado algunas cuestiones sobre estructura social de la ciudad y su región en nuestra tesis doctoral La Extremadura soriana y su ámbito a fines de la Edad Media, Universidad Complutense, Madrid, 1992, t. I. pp. 788 y ss. En algunos de nuestros artículos hemos abordado también algunas cuestiones parciales relacionadas con la historia de la burguesía mercantil soriana en el siglo XVI. En «El Común de los pecheros de Soria en el siglo XV y primera mitad del XVI», Hispania, 174 (1990), pp. 39-92. "Los judeoconversos en Soria después de 1492", Sefarad, 51 (1991), pp. 259-98. «El comercio de las lanas churras en el ámbito soriano durante el siglo XVI» Cbronica Nova, 19 (1991), pp. 87-112.Y "Desarrollo de la industria pañera en Soria en el siglo XVI", Celtiberia, 87-88 (1994), pp. 105-30. 
del reino de Castilla, dar cuenta del papel que desempeñaron los hombres de negocios sorianos en el comercio lanero en todas sus vertientes.

Hasta ahora los trabajos de investigación que más atención han prestado al análisis de las consecuencias que sobre la organización socioeconómica de una ciudad castellana tuvo su involucración en el comercio lanero se han centrado en el caso singular de Burgos, ciudad donde predominaron en los siglos XV y XVI los mercaderes exportadores ${ }^{10}$. Por el contrario las otras ciudades castellanas vinculadas de una u otra manera con este comercio no han sido apenas objeto de atención desde este punto de vista, salvando algunos trabajos de carácter parcial dedicados a Segovia, ciudad en la que por lo demás siempre ha llamado más la atención la figura del fabricante pañero que la del mercader lanero ${ }^{11}$. Por esta razón presenta interés en el actual contexto historiográfico dedicar un análisis monográfico a la ciudad de Soria, que ofrece una evidente singularidad frente a Burgos y a Segovia, y por supuesto también frente a otras ciudades de su entorno vinculadas con el comercio de la lana, como por ejemplo Nájera, Logroño, Vitoria y Bilbao' ${ }^{12}$.

\section{LOS MERCADERES SORIANOS EN LA EXPORTACIÓN DE LANAS}

A pesar de que la fase de exportación, tanto a la Europa atlántica como a Italia, ha sido la que más interés ha suscitado en los investigadores del comercio lanero en la Castilla del siglo XVI, no es mucho lo que sabemos sobre los sistemas de contratación empleados por los mercaderes exportadores, en su relación tanto con ganaderos y mercaderes proveedores como con fabricantes pañeros en los puntos de destino, y sobre la propia identidad de estos mercaderes, debido a que el tipo de fuente documental hasta ahora manejado preferentemente, los registros de pago de derechos de aduana, no resultan muy ricos en

to Sobre el papel político de los mercaderes burgaleses en su ciudad trata GuERrEro NAVARRETE, Y.: Organización y gobiemo en Burgos durante el reinado de Enrique IV de Castilla (1453-1476), Madrid, 1986. Vid. también BONACHiA HERNANDO, J.A.: «Algunas cuestiones en torno al estudio de la sociedad bajomedieval burgalesa" La ciudad de Burgos. Actas del Congreso de Historia de Burgos, Junta de Castilla y león, 1985, pp. 37-55. La obra que más profundiza en el análisis del papel de los mercaderes burgaleses como exportadores de lana es BASAS FERNÁNDEZ, M.: El Consulado de Burgos en el siglo XVI, Madrid, 1963 . Un estado de la cuestión reciente sobre esta problemática en CAUNEDO DEL POTRO, B.: «Mercaderes burgaleses en el tránsito a la modernidad. Notas sobre el estado de la cuestión" Hispania, 175 (1990).

11 Vid. RODENAS VILAR, R.: op. cit.

12 Sobre Nájera se dispone de un pequeño trabajo monográfico de interés. BrUMONT, F.: «La laine dans la région de Nájera (Deuxième moitié du XVIe. siècle» Actar del ll Coloquio de Metodología Histórica Aplicada. La documentación notarial y la bistoria, Santiago de Compostela, 1984, pp. 317-22. Para las otras ciudades no conocemos trabajos de interés sobre esta cuestión. 
informaciones que pudiesen contribuir a resolver estas cuestiones ${ }^{13}$. Sólo una explotación intensiva de los protocolos notariales de las ciudades castellanas vinculadas al comercio lanero, y de otras fuentes documentales semejantes de Italia, Francia y Países Bajos, podría contribuir decisivamente a mejorar nuestros conocimientos al respecto, además por supuesto de la localización de libros de cuentas y correspondencia de mercaderes, por desgracia no demasiado frecuentes en los archivos accesibles a los investigadores. Dado que nosotros para la elaboración del presente trabajo sólo hemos manejado de forma exhaustiva los protocolos notariales sorianos, no hemos tenido oportunidad de reconstruir una imagen completa del papel de los mercaderes de Soria en la exportación de lanas. Pero, no obstante, hemos localizado en ellos múltiples noticias que demuestran que, en contra de lo que hasta ahora se creía, en esta ciudad hubo en el siglo XVI, y continuó habiéndolos en los siglos siguientes, mercaderes que de forma más o menos ocasional participaron directamente en negocios de exportación de lana, formando en ocasiones compañía con mercaderes exportadores avecindados en otras ciudades castellanas, o incluso fuera del reino, preferentemente en Francia.

Uno de los primeros mercaderes sorianos de los que tenemos constancia sobre su dedicación a la exportación de lanas a Flandes es Antonio Beltrán, individuo de origen judío, quien siendo niño marchó con su familia a Portugal en 1492, para regresar con ella al año siguiente convertidos todos al cristianismo. En 1516, cuando se presentó como fiador para el arrendador de las salinas de Atienza, varios testigos declararon que era hombre muy rico que tenía fama de poseer más de 30.000 ducados «en dinero y en sacas de lana que envía a Flandes» ${ }^{14}$. Y en 1547 , al realizarse el inventario de sus bienes con ocasión de la muerte de su mujer María de Ribera, eran muchas las deudas que con él tenían contraídas personas avecindadas o estantes en Flandes ${ }^{15}$.

Sus hijos y demás descendientes no siguieron sin embargo su ejemplo, a juzgar por las noticias documentales de que disponemos, y en las décadas centrales del siglo XVI son representantes de otras familias sorianas los que aparecen involucrados en negocios de exportación, como por ejemplo Pedro Larios,

13 Para el siglo XVI la obra que más en profundidad analiza el comercio exportador lanero es la de H. LAPEYRE, El comercio exterior de Castilla a tratés de las aduanas de Felipe II, Valladolid, 1981. También resulta de interés BASAS FernÁnDEZ, M.: El Consulado... Sobre el siglo XVI Vid. BlLBAO BILBAO, L.M.: «Exportación y comercialización de lanas de Castilla durante el siglo XVII (16101720)» en El pasado bistórico de Castilla y León, vol. 2, Burgos, 1983, pp. 225-243.

14 Estas declaraciones en AGS, EMR, Hojas e Informaciones, leg. $577-1^{\circ}$. Vid. nuestro artículo «El ascenso sociopolítico de los judeoconversos en Castilla en el siglo XVI. El ejemplo de la familia Beltrán en Soria», Sefarad, LVI, 2 (1996), pp. 227-250.

15 Este inventario en AHPS, C. 3519-7.Las cantidades debidas por estos deudores de Flandes eran muy elevadas. Por ejemplo Juan de Bilbao debia por una partida 3.424 .900 mrs. y por otra $2.683 .958 \mathrm{mrs}$. 
los hermanos Juan y Alonso Núñez, Diego Ruiz, Pedro de Santa Cruz o Diego de San Juan ${ }^{16}$.

A esta generación de exportadores sorianos de los años centrales del siglo XVI, sobre cuyas actividades de exportación los protocolos notariales no aportan mucha información, siguió en la segunda mitad del siglo otra generación de la que los representantes más destacados serían a nuestro juicio Domingo del Águila y Juan García de Tardajos, el menor. Las noticias relativas a estos dos individuos que hemos logrado reunir son bastante más numerosas, aunque todavía quedan bastantes aspectos por esclarecer sobre sus biografías. Basándonos en abundantes indicios, aunque no en pruebas concluyentes, presumimos que ambos tenían un origen judeoconverso ${ }^{17}$. Y quizás esta circunstancia les ayudó a entrar más fácilmente en contacto a fines del siglo XVI con los mercaderes portugueses descendientes de judíos que entonces acudieron en gran número a Soria y su región para comprar lanas, que luego enviaban a sus familiares asentados en ciudades de la Europa atlántica, como Bayona, San Juan de Luz o Rouen, para desde allí revenderlas a los fabricantes de paños.

En el caso de Domingo del Águila las relaciones comerciales con los judeoconversos portugueses fueron menos determinantes para su involucración en el comercio de exportación de lanas a los puertos atlánticos europeos, puesto que para él tuvo mucha más importancia su vinculación con el mercader de origen francés asentado en Medina del Campo, Hilario Bonafont, y con los mercaderes también franceses Francisco y Bernardo de Nebrese, uno de los cuales, Francisco, ya había tenido contactos con mercaderes sorianos al establecer el 7 de febrero de 1571 una compañía con los hermanos Núñez, vecinos de Soria, para exportar lanas de la región soriana a Rouen ${ }^{18}$. La primera referencia do-

16 Aporta algunos datos sobre pagos de derechos aduaneros por estos individuos LAPEYRE, $\mathrm{H}$.: en op. cit. Sobre Pedro Larios, que también fue un activo mercader de lana churra junto con su hermano García Larios tratamos en «El comercio de las lanas churras...*. Sobre los hermanos Núñez, que en 7-II-1571 formaron una compañía con los Nebreses para exportación de lanas Vid. FaLAH HASSAN ABED AL-HUSSEIN «Las ferias de Medina y el comercio de la lana: 1514-1573", en Historia de Medina del Campo y sw Tierra, II, Valladolid, 1986,pp. 29-30. Sobre Diego Ruiz vid. la carta de pago otorgada por su viuda en 6-V-1574 a Pedro de Santa Cruz, de lo que éste había cobrado de las sacas de Flandes. AHPS, PN, 65-147-386. Diego de San Juan y Pedro de Santa Cruz fueron accivos hombres de negocios que trabajaron preferentemente al servicio de grandes mercaderes exportadores, como el burgalés Cristóbal Cerezo, y también de los principales señores de ganados sorianos, como Juan de Vinuesa o Alonso de Río, representando sus intereses en las ferias de Medina.

17 Sobre el posible origen converso de los García de Tardajos ya tratamos en «Los judeoconversos en Soria después de 1492n Sefarad, 51 (1991), pp. 275 y ss. Domingo del Águila estuvo emparentado con familias de apellidos Núnezz y Molina, sobre cuyo posible origen converso también tratamos en ese artículo. El apellido Del Águila también fue adoptado por judeoconversos de lugares del entorno soriano, como por ejemplo Atienza.

18 Sobre la intensa actividad exportadora de Francisco de Nebrese (Nebrèze), miembro de una familia de papeleros de la región de Thiers, llama la atención LAPEYRE, H.: op. cit. p. 105. Indica que entre 1575 y 1579 expidió más de 3.000 sacas de lana. 
cumental encontrada que nos muestra a Domingo del Águila relacionado con los Nebrese data de $1581^{19}$, pero a ella le siguen otras varias, y sobre todo noticias referentes a su actuación conjunta con Hilario Bonafont, quien tuvo establecida una compañía con estos mismos Nebrese para el trato en distintas mercancías, entre las que destacaban las lanas castellanas, que funcionó entre 1579 y $1585^{20}$. Después de quedar disuelta esta compañía Hilario Bonafont continuó exportando importantes cantidades de lana a muy diversos destinos tanto en Italia como en Francia, pero entonces casi siempre conjuntamente con Domingo del Águila, a nombre del cual se registraban con frecuencia las exportaciones ${ }^{21}$.

Además, tras la muerte de Hilario Bonafont en 1599, Domingo del Águila continuó llevando adelante la mayor parte de sus negocios, y en agosto de 1601 consiguió incluso contraer matrimonio con su viuda María Ferrer, pasando a residir en estos primeros años del siglo XVII con frecuencia en Medina del Campo. Y por otra parte prueba que su posición en esta relación de negocios con las familias francesas de Bonafont y Nebrese no fue la del simple agente instalado en Soria para captar las pequeñas partidas de lana de los ganaderos serranos, el hecho de que su hijo Gregorio de Molina fuese identificado en una carta de poder del año 1600 como residente en Rouen y miembro de una compañía en la que también se integraban Francisco y Juan de Nebrese ${ }^{22}$.

Estas estrechas vinculaciones con los Bonafont y los Nebrese no impidieton sin embargo a Domingo del Águila negociar por su cuenta la comercialización de determinadas partidas de lana, como consta que hizo en 1595 al concertarse el 17 de junio de ese año con dos portugueses residentes en Soria, Juan Rodríguez y Pedro Gómez, para que le vendiesen las sacas «refloretas y floretas» de

is AHPS, PN, 82-186-43.

20 En los primeros años del siglo XVII Francisco Nebrese, señor de La Batisa, estuvo siguiendo pleito contra los herederos de Hilario Bonafont por razón de ajuste de cuentas de la compañia que ambos habían tenido. Con motivo de la tramitación del pleito se aportaron múltiples escrituras, y entre ellas el contrato original en francés de fundación de la compañia, fechado en Thiers, 28-XI1579, y su traducción al castellano. También se aportó un balance y fenecimiento de cuentas de la compañía, fechado en 1589. Vid. AChV, P.C. Taboada, F. 1483-1.

${ }^{21}$ Numetosas referencias a estas exportaciones se pueden encontrar en el memorial de bienes y hacienda que dejó a su muerte en 1599 Hilario Bonafont, aportado como prueba en un pleito. En AChV, P.C. Taboada F. 1843-1, fols. 184 y ss. Entre los bienes inventariados destaca utun libro grande de caxa con su manual en que se escrivían sus negoçios particulares y en que estavan particularmente asentadas las quentas de las lanas que por su quenta en compañía de differentes personas ha enbiado fuera del reino y los retornos que se le haçian en dineros y mercaderías". Abundan en este inventario referencias a envíos de sacas de lana por Domingo del Águila a Florencia, Milán, Amberes, Patís y Bilbao, entre otros destinos. En la mayor parte de los casos se indica que, aunque el envío se efectuaba a nombre de Dorningo del Águila, la pérdida o ganancia de la venta se repartía a medias entre él e Hilario Bonafont.

22 Se trata de una carta de poder otorgada por el alférez de Soria, Antonio López de Rio, a estos tres individuos, entonces residentes en Rouen, para cobrar deudas de unos mercaderes de San Juan de Luz y Bilbao a los que había comprado lanas, en AHPS, PN, 93-206-144.

Hispania, $1 \mathrm{X} / 2$, aúm. 205 (2000) 479-514 
lana y añinos que él había de llevar a los puertos de San Sebastián y Bilbao. La operación de venta se había de realizar en estos puertos, y el comprador debería pagar al contado, en dinero o en mercancías, compensándose a estos dos agentes de ventas por su «trabajo y administración» con un $2 \%$ del valor total de la operación, además de con el pago de los gastos ocasionados durante su estancia en los puertos ${ }^{23}$.

Con anterioridad por su parte consta que Domingo del Águila había exportado lanas por su cuenta a Italia, a través de los puertos de Yecla y Alicante, entre los años 1589 y $1592^{24}$, aunque al mismo tiempo también estuvo colaborando estrechamente con Hilario Bonafont en negocios mercantiles con ciudades italianas, centrados sobre todo en la exportación de lana castellana e importación de otras mercancías obtenidas a cambio de ésta ${ }^{25}$.

Juan García de Tardajos, miembro de una familia que llevaba varias generaciones negociando con lanas, aunque a escala sobre todo local y comarcal, también dio a finales del siglo XVI el salto a los negocios de exportación, tanto hacia Italia como hacia los puertos del Atlántico. En concreto nos consta que antes de 1597 debió remitir lanas a Florencia a las casas de Juan Luis Vitoria y Juan López de Oreitia, por un lado, y de Antonio Buelta y Juan González de Albelda por otro, que le fueron pagadas con posterioridad a través de un complicado procedimiento, que le llevó a adquirir un juro al quitar de 3.070.084 mrs. de principal y $219.343 \mathrm{mrs}$. de renta anual, a razón de $14.000 \mathrm{mrs}$. el millat ${ }^{26}$. En los años siguientes continuó con estos negocios, y así lo demuestran por ejemplo contratos concertados con carreteros para el transporte de

23 El contrazo firmado en Soria, 17.VI-1595, en AHPS, PN, 202-416-75.

24 Según LAPEYRE aparece pagando derecho de aduana en 1589, 1590, y 1591 . Por nuestra parte en los protocolos notariales hemos encontrado las siguientes referencias de interés. En 1590 exporta 4.000 a. limpias a través de Yecla (AHPS, PN, 178-370-162). En 1591 hace llevar a Alicance 178 sacas de lana lavada de 12 arrobas cada una, con muy diversos carreteros (236-478, fols. $103,105,107$ y 111). En 1592 contrata con unos carreteros de Salduero el transporte de 46 sacas a Fuencidueña, en la provincia de Madrid. Desde aquí continuarían viaje hacia algún puerto meditetráneo (236-478-232).

25 Para el seguimiento de los negocios en Italia de Domingo del Águila e Hilatio Bonafont tesultan de gran interés unas series de cartas de negocios aportadas como prueba en varios pleitos de Chancillería. Destacan en primer lugar varias cartas enviadas desde Florencia en los años 1592 y 1593 a Hilario Bonafont por su agente en esa ciudad italiana, en las que le informa sobre el proceso de venta de sus lanas castellanas, entre ellas las de un gran ganadero soriano, el alférez Francisco López de Río. Abundan en estas cartas también las referencias a Domingo del Águila, quien no cabe duda que actuaba conjuntamente con Hilario Bonafont. En AChV, P.C. Pérez Alonso, F. 1.401-3, fols. 119 y ss. También presentan interés las cartas que el propio Domingo del Águila envió a Bonafont en 1598 y 1599, en las que abundan referencias a negocios con Italia y con otras partes de Europa. Vid. AChV, P.C. Taboada, F. 1.483-1, fols. 305 y ss.

${ }_{26}$ Según consta por doc. de AHPS, PN, 259-528-28. Consta también que en el verano de 1595 hizo transportar bastante lana al puerto de Alicante, por varios contratos concertados con carreteros en AHPS, PN, 202-415 y 416.

Hispania, LX/2, núm. 205 (2000) 479-514 
lana en dirección hacia los puertos del Mediterráneo, o noticias sobre el cobro de letras despachadas en Florencia ${ }^{27}$.

Las referencias a su participación en negocios de exportación a través de los puertos cantábricos son más escasas, pero suficientemente significativas. En concreto nos consta que en 1581 entró en tratos directos con un mercader francés de Toulouse, Guillermo de Lestrada, a quien ofreció entregarle 247 arrobas y media de lana en Bilbao a cambio de 22 cargas y media de pastel, puestas también en esta misma villa portuaria, a razón de 11 arrobas de lana por carga ${ }^{28}$.Y más adelante envió algunas pequeñas cantidades de lana al puerto francés de Rouen para que desde allí se las vendiesen por cuenta suya, aprovechando los vínculos de negocios que le unían con algunos judeoconversos portugueses instalados en esta ciudad, a los que sirvió como agente en Soria. En concreto sabemos que fue un directo colaborador del portugués Antonio Brandon, quien tuvo una activa presencia por tierras sorianas como comprador de lanas en los últimos años del siglo XVI y primeros del siglo XVII. Y aprovechando esta circunstancia envió en alguna ocasión a Rouen sus propias lanas junto con las del portugués, para que allí fuesen recibidas todas juntas por otro judeoconverso, Francisco Méndez de Soto, quien se ocuparía de venderlas y transferir el producto de la venta a Antonio Brandon, el cual a su vez pagaría a Juan García de Tardajos lo que le correspondiese por las suyas propias ${ }^{29}$.

En conjunto la actividad exportadora de los mercaderes de lanas sorianos estuvo muy diversificada, puesto que consta que tuvieron negocios con bastantes ciudades de Italia, Francia y Flandes, de distinta intensidad en los diferentes momentos del siglo XVI, advirtiéndose una mayor orientación hacia Flandes a comienzos de siglo, y hacia Italia a finales. La dedicación de las distintas familias a esta actividad tuvo por lo demás un grado de continuidad muy variable, ya que frente a casos de familias rápidamente enriquecidas, que abandonaron pronto el comercio lanero, como les ocurrió a los Beltranes o a los Núnez, también hubo otras que trataron en lanas a lo largo de varias generaciones, hasta

${ }^{27}$ En julio de 1600 contrata a varios carreteros para llevar a Fuentidueña 72 sacas de lana. Se trata de Fuentidueña de Tajo, en la actual provincia de Madrid, desde donde presumiblemente se dirigirian hacia Alicante. Vid. AHPS, PN, 209-429-167). En marzo de 1602 Juan García de Tardajos da poder al licenciado Juan García, médico, y a Francisco de la Peña para cobrar de Juan de Lisboa, residente en Corte, los maravedíes que montasen 435 escudos y un sueldo a razón de 398 mrs. por escudo, que se le debían por letra que sobre él dio Antonio Texeira, fechada en Florencia el 15-XII-1601. AHPS, PN, 137-288-310.

28 AHPS, PN, 82-186-292. Finalmente Lestrada sólo le pudo entregar 11,5 cargas de pastel, y en compensación se obligó a pagarle las otras 121 arrobas de lana a 18 reales.

29 Así nos consta por la carta de finiquito otorgada en Soria el 23-VIII-1612 a Antonio Brandon por María de Soria, viuda de Juan García de Tardajos, donde se hace constar que éste había enviado a Rouen por hacienda propia, aunque por orden de Antonio Brandon, 18 sacones y medio de lana extremeña lavada, que recibió en Rouen Francisco Méndez Soto. Entonces quedaban por cobrar todavía de esta lana 103 escudos franceses, que debía enviar Francisco Méndez Soto a Brandon, y éste a su vez entregaría luego a María de Soria. Vid. AHPS, PN, 345-642-682.

Hispania, LX/2, núm. 20 (2000) 479-514 
bien entrado el siglo XVII, como fue precisamente el caso de las de Juan García de Tardajos y Domingo del Águila.

La extraordinaria importancia que la ciudad de Soria llegó a adquirir en el transcurso del siglo XVI como centro canalizador del comercio exportador lanero, se tradujo incluso en el ocasional avecindamiento en ella de algunos notables exportadores burgaleses, como fue el caso de Cristóbal de Cerezo, casado en segundas nupcias con una viuda perteneciente a una familia de la oligarquía soriana, Ana de Vinuesa ${ }^{30}$.

\section{LOS MERCADERES SORIANOS COMO INTERMEDIARIOS PARA LOS MERCADERES EXPORTADORES DE LANAS}

A pesar de que la presencia de mercaderes exportadores en la ciudad de Soria en los siglos XVI y XVII fue mayor de lo que hasta ahora se pensaba, no deja de resultar sin embargo cierto que la mayor parte de las lanas puestas a la venta por los ganaderos trashumantes sorianos, sobre todo de las procedentes de los grandes rebaños, eran adquiridas directamente por mercaderes foráneos, que frecuentemente contaban con un factor instalado en Soria, en el que delegaban la gestión de casi todas las tareas relacionadas con el recibo, lavado, ensacado y transporte de las lanas ya lavadas a los puertos.

La procedencia de estos mercaderes foráneos fue variando a lo largo del tiempo, advirtiéndose una preponderancia indiscutida de los mercaderes burgaleses hasta la década de 1570 , y una mayor diversificación de la procedencia en las últimas décadas del XVI, durante las que por otra parte se va fraguando el avance, luego imparable, de los judeoconversos portugueses, hegemónicos en las primeras décadas del XVII ${ }^{31}$. En contrapartida muchos de los que actuaban como factores en Soria aparecen con mayor continuidad, hasta el punto de que algunas familias estuvieron vinculadas a esta actividad a lo largo de varias generaciones, dándose el caso, no obstante, de que las más representativas entre ellas coinciden en ser las mismas que proporcionaron a Soria los pocos mercaderes exportadores con que contó en esta época.

Los factores de los mercaderes exportadores solían ser personas arraigadas en la sociedad soriana, buenos conocedores de los entresijos del negocio lanero, al menos en sus primeras fases de contratación con los ganaderos, recibo y lavado. Por ello no era extraño que los mercaderes foráneos, al adentrarse en el

30 De hecho al casarse Cristóbal de Cerezo con Ana de Vinuesa hacia 1562 el matrimonio fijó su residencia en Burgos, si bien al cabo de algunos años pasaron a vivir a Soria, en donde este mercader compraba y lavaba la mayor parte de las lanas que luego exportaba hacia Flandes. Nos basamos en datos de un pleito en $\mathrm{AChV}$, P.C. Ceballos, leg. 36.

31 Hemos estado trabajando en los últimos años en la identificación de los mercaderes exportadores de lanas sorianas en los siglos XVI y XVII en el marco de un proyecto de investigación de la Fundación Duques de Soria.

Hispania, LX/2, núm. 205 (2000) 479-514 
negocio de exportación de lanas sorianas, tratasen de ponerse en contacto con las familias locales para atraerlas a su servicio, en lugar de llevar a sus propios hombres a Soria, por estar menos familiarizados con el entorno. Por supuesto entre los mercaderes exportadores hubo también diferencias en cuanto al grado de dedicación personal al negocio lanero, puesto que algunos hacían acto de presencia con frecuencia por tierras sorianas para supervisar personalmente su negocio, mientras que otros delegaban totalmente en sus factores, aunque este caso fue más habitual en el siglo XVII entre los mercaderes instalados en Madrid, mientras que en el XVI burgaleses y riojanos hacían sentir mucho más su presencia en tierras sorianas.

En cualquier caso la asunción por muchos hombres de negocios sorianos del papel de factores al servicio del mercader exportador de turno, fuese éste burgalés, portugués, francés o navarto, limitó pot un lado las posibilidades de crecimiento económico de la ciudad y su entorno, por múltiples razones que sería prolijo enumerar aquí. Pero por otro permitió al menos que una pequeña fracción de los beneficios del comercio lanero revirtiese sobre la propia sociedad soriana a través de la generación de puestos de trabajo estacional, relacionados con el esquileo, lavado, ensacado y transporte de lana, y de la percepción por los hombres de negocios sorianos de las plusvalías generadas en estas fases primeras del proceso de elaboración y comercialización de la lana. Por supuesto para la sociedad soriana hubiese resultado mucho más positivo que una mayor parte de la lana producida en su entorno hubiese sido trabajada por pañeros locales, pero al menos, gracias a la abundancia de factores entre sus hombres de negocios, se consiguió que los primeros pasos en la elaboración de esa lana se efectuasen en los lavaderos sorianos y no en los de Burgos, Nájera o cualquier ciudad navarra, aunque es cierto que un elemento que favoreció decisivamente esta situación fue que el transporte de la lana lavada resultaba mucho más barato que el de la sucia ${ }^{32}$. Con todo no hay que olvidar que otros ámbitos de pastos de verano resultaron todavía mucho menos favorecidos que Soria, porque los ganados trashumantes llegaban a ellos en verano ya esquilados, como era el caso de la mayoría de los que pastaban en las montañas de León, que solían ser despojados de su lana en los esquiladeros del Sistema Central, sobre todo de Segovia.

Por otra parte hay que hacer constar que no todos los hombres de negocios sotianos de los que se sirvieron los mercaderes exportadores foráneos para captar las grandes partidas de lana de los rebaños trashumantes asumieron el papel de simples factores, sino que bastantes de ellos actuaron como auténticos mercaderes intermediarios, que solían adquirir la lana de los pequeños ganaderos trashumantes adelantándoles dinero en otoño o primavera, y luego, una vez recibida, procedían a revenderla en el transcurso del verano a mercaderes forá-

${ }^{32}$ No obstante, esta circunstancia no impedía que en ocasiones determinados mercaderes prefiriesen transportar las lanas en sucio a sus lavaderos en Burgos o Segovia.

Hispania, LX/2, núm. 205 (2000) 479-514 
neos exportadores, que no solían pagar al contado sino que por el contratio suscribían contratos de obligación de pago aplazado ${ }^{33}$. Por consiguiente, estos mercaderes intermediarios necesitaban disponer de un cierto excedente de capital para financiar estas operaciones, dado que en última instancia la razón de ser de su negocio estribaba en aprovechar situaciones de coyuntural carencia de capital tanto entre los pequeños ganaderos como entre los mercaderes exportadores, para imponerles condiciones de contratación favorables para ellos como intermediarios. De hecho consta que estos mercaderes no sólo empleaban en estos tratos su capital propio y el de su familia, sino también el de otras personas que se lo cedían para que lo invirtiesen a pérdida o ganancia ${ }^{34}$. Las fortunas de muchos hombres de negocios sorianos del siglo XVI y del XVII fueron, en parte al menos, resultado del éxito en esta actividad, pero no cabe duda de que en el transcurso de estos dos largos siglos se sucedieron épocas desigualmente favorables para este negocio, y de momento no estamos en condiciones de efectuar un seguimiento pormenorizado del proceso. En cualquier caso los protocolos notariales demuestran que los mercaderes sorianos del XVI revendían lana a los exportadores, al principio casi siempre burgaleses y en las últimas décadas con cada vez más frecuencia portugueses ${ }^{35}$, y competían con ellos por captar las

33 Los protocolos notariales sorianos del siglo XVI no permiten conocer en detalle los entresijos de este negocio de los intermediarios, por no resultar suficientemente abundantes. Para las primeras décadas del siglo XVII sin embargo sí aportan numerosos datos, que analizaremos en profundidad en próximos trabajos. En concreto hemos recogido gran cantidad de noticias sobre la actividad de contratación del licenciado Juan García médico, que cubren las tres primeras décadas del siglo XVII, e incluso algunos de los últimos años del XVI, en que actuaba conjuntamente con su tío Juan García de Tardajos, el menor.

34 El 26-II-1601, Juan de Salazar, miembro de la oligarquía soriana y señor de vasallos, entregó a Ana de Lumbreras y a su hijo Hernando Ibáñez, mercaderes sorianos, 750 ducados para que tratasen con ellos a pérdida o ganancia, a repartir a medias entre las dos partes. Puso como condición que sólo pudiese tratar con ese dinero en lana y añinos, y que en los contratos que no fuesen al contado se le consultase su parecer, puesto que si se fiaba sin su orden y había riesgo en la operación éste sería por cuenta de Hernando Ibáñez. AHPS, PN, 95-212. Este mismo Hernando Ibáñez y su madre recibieron en 4-XI-1600 de Francisco de Molina 646.000 mrs.(AHPS, PN, 93-208). Los dos Juan García de Tardajos, padre e hijo, también recibieron grandes cantidades de dinero para emplear en trato de lanas, a pérdida o ganancia. En 9-IX-1564 Juan García de Tardajos estableció una compañía con el regidor Nicolao Beltrán de Ribera, descendiente de judeoconversos metcaderes de lanas, en la que él puso 75.000 mrs. y el regidor 150.000 . Más adelante volvieron a establecer nueva compañía en la que esta vez Nicolao invirtió nada menos que 40.000 reales. Vid. nuestro art, «E! ascenso sociopolítico de los judeoconversos.... Francisco de Molina por su parte entregó en 29-VII1599 a Juan García de Tardajos, hijo, I.000 ducados para que los invirtiese durante un año. AHPS, PN, 93-206-245. En 15-IX-1594 Alonso de Molina entregó a Domingo del Águila 600.000 mrs. para invertir en tratos de "paños, sedas y lanas». AHPS, PN, 241-483.

35 Entre otros ejemplos podemos citar la venta en el verano de 1566 por el escribano Alonso Núñez al burgalés Cristóbal Cerezo de 3.483 arrobas de lana extremeña, riberiega y churra, toda ella lavada, que cobró a plazos en las ferias de Medina del Campo. AHPS, PN, 76-172. Este mismo vendió en 1570 a un vecino de Segovia 985 arrobas. AHPS, PN, 77-194-133. En 1595 Juan García 
lanas de los medianos propietarios, consiguiendo algún año incluso comprar a los grandes ganaderos, que por lo general tendían a vender sus lanas fuera de Soria ${ }^{36}$. Estos mercaderes en su mayoría coinciden en ser los mismos que hemos identificado como exportadores, aunque siempre hay alguna excepción, como la del licenciado Juan García, médico, a quien nunca hemos encontrado embarcado en empresas exportadoras. Pero esta constatación simplemente nos viene a probar que los hombres de negocios sorianos diversificaban enormemente sus actuaciones e inversiones, adoptando una actitud sumamente versátil, que les permitía unas veces servir como factores a un mercader exportador, otras revenderle lanas, y otras por fin aventurarse a exportarlas directamente, solos o en compañía con otros mercaderes foráneos.

Hay que tener en cuenta por fin que el negocio de los intermediarios presentaba múltiples variantes, que la documentación consultada sólo nos ha permitido conocer con desigual detalle. En el nivel menos desarrollado el intermediario se limitaba a concertar la compra adelantada de sus lanas a los pequeños ganaderos en otoño, y antes incluso de haberlas recibido traspasaba los contratos de obligación a otro mercader para que éste se encargase de recibirlas y luego transportarlas a los lavaderos. En otras ocasiones el intermediario revendía las lanas en sucio adquiridas por este mismo procedimiento al mercader exportador, después de que los ganados ya habían sido esquilados, pero estando todavía las lanas desperdigadas por los esquiladeros de los pueblos, aunque en otros muchos casos él mismo asumía la tarea de transportatlas a sus lonjas en Soria, para que desde éstas el comprador las llevase más fácilmente a los lavaderos. Los tres lavaderos que nos consta que existieron en Soria en los siglos XVI y XVII fueron propiedad en todos los momentos de mercaderes ${ }^{37}$, y por ello no resulta sorprendente que con bastante frecuencia determinados intermediarios sorianos revendiesen las lanas ya lavadas y ensacadas a los exportadores, pudiéndose concertar la entrega en la propia ciudad de Soria o en los puertos del Cantábrico, preferentemente Bilbao. Y en este último caso la posición del mercader soriano resultaba ya muy próxima a la del exportador, por lo que casi siempre los individuos que encontramos efectuando este tipo de

de Tardajos y el licenciado Juan García médico vendieron a portugueses 1.204 arrobas de añinos extremeños y tiberiegos. AHPS, PN, 202-415, Soria 24-IX-1595.

36 Por ejemplo en 28-VI-1559 Juan García de Tardajos compró a Alonso de Río 607 arrobas de lana extremeña, y a Andrés Calderón 695. AHPS, PN, 13-31-29. En 1550 los hermanos Mateo y Bartolomé Sánchez y Pedro Larios compraron 440 arrobas al regidor Jorge de Beteta. AHPS, PN, 23-53-209.

37 Los protocolos sorianos aportan noticias que prueban que en la segunda mitad del siglo XVI fueron propietarios de lavaderos a las orillas del Duero en Soria Domingo del Águila, Juan García de Tardajos y Alonso Núñez. Posteriormente también adquirió un lavadero Simón Fernández de Oporto, judeoconverso portugués instalado en Soria. Todos estos lavaderos fueron cambiando de propietarios en el transcurso del siglo XVH. Fuera de la ciudad, en las aldeas de su Tierra, había otros varios importanses lavaderos. 
reventas, con entrega concertada en los puertos, son los mismos que en otros casos podemos identificar como exportadores.

\section{LOS MERCADERES GANADEROS.}

Al analizar la composición del grupo de los hombres de negocios, o burguesía mercantil, en Soria un hecho singular que se constata a lo largo de los siglos es el de la existencia de familias que combinaron la dedicación al comercio con la explotación de rebaños de ganado trashumante, que en ocasiones llegaron a comprender un elevado número de cabezas, aunque nunca tantas como los de las familias hidalgas ganaderas más encumbradas de la ciudad y su Tierra ${ }^{38}$. Además la dedicación a la cría de ganado trashumante por parte de estas familias de mercaderes no presenta por lo general el grado de continuidad a lo largo de muchas generaciones que se advierte entre las familias ganaderas del estamento noble, muchas de ellas con fuertes vinculaciones rurales. Por el contrario las inversiones en ganados trashumantes por parte de algunos mercaderes presentan una evidente motivación especulativa, según demuestra por ejemplo el caso del judeoconverso Antonio Beltrán, quien compró unas 2.000 cabezas con su posesión en La Serena en 1524 a precio de nueve reales por cabeza y a los pocos años las volvió a vender a razón de 12 reales por cabeza ${ }^{39}$.

$\mathrm{Si}$, además, la gestión de sus cabañas por parte de estas familias de mercaderes era llevada a cabo de una forma más racionalizada y orientada sistemáticamente a la obtención del máximo beneficio, aprovechando las tendencias del mercado, es algo que resulta difícil determinar con precisión con la documentación disponible. Pero no cabe duda de que el propio hecho de que estas familias invirtiesen deliberadamente en la compra de rebaños se puede interpretar como indicio de que actuaban movidos por el deseo de la obtención de máximos beneficios, pues de lo contrario hubiesen optado por la compra de tierras o juros, que garantizaban unos rendimientos menos inciertos que la ganadería trashumante, aunque quizás más modestos. Existe constancia documental por lo demás de que la explotación de una cabaña trashumante fue entendida por los hombres de negocios sorianos del siglo XVI como un negocio susceptible de ser llevado en compañía, al igual que otros del estilo del comercio de paños o el

38 La existencia de mercaderes propietarios de ganados está también constatada en otras ciudades del entorno de Soria. Así entre los burgaleses del siglo XVI BASAS menciona a Diego López Gallo o Francisco de Brizuela. Vid. BASAS, M.: op. cit. capítulo «Burgos en el comercio lanero...*. En Medina de Ríoseco desraca la figura de Gaspar Enrique, banquero, comerciante y propiecario de ganados. Vid. Falah HaSSAN ABED AL-Hussein, «Las ferias de Medina...» p. 24. Orro ejemplo interesante nos lo ofrece Zaragoza. Vid. GOMEZ ZORRAQUINO, J.I.: La burguesia mercantil en el Aragón de los siglos XVI y XVII (1516-1652), Zaragoza, 1987, p. 79.

39 Más detalles sobre esta operación especulativa en nuescro libro Soria en la Baja Edad Media. Espacio rural y economia agraria, Madrid, 1993, p. 175. 
comercio de lana. Y así nos consta por un documento del 11 de enero de 1600 que Ana de Lumbreras, viuda del mercader Pedro Ibáñez, y su yerno Sebastián de Salcedo habían tenido desde hacía 10 años compañía easí en ganados como en arrendamientos y obligados que han sido de las carnicerías", a pérdida y ganancia por mitad, la cual habían decidido entonces disolver ${ }^{40}$. $Y$ precisamente esta misma Ana de Lumbreras consta que había participado en otras compañías, sobre todo con su hijo Hernando Ibáñez, que se concentraban en el trato de paños, o en la compraventa de lana.

Los mercaderes sorianos propietarios de rebaños ovinos trashumantes no pudieron rivalizar en el siglo XVI con los hidalgos de las tradicionales familias ganaderas, como los Ríos o los Vinuesa, por el número de cabezas poseído y cantidad y calidad de los derechos de posesión reconocidos en Extremadura. Pero excepcionalmente algunos de ellos llegaron a convertirse en propietarios de gran talla, y tuvieron acceso a algunas de las dehesas del Sur que más trataban de acaparar para sí las familias de los «magnates ganaderos». Para los primeros años del siglo XVI así lo prueba la figura de Gabriel de Cuenca, metcader que partiendo de la nada llegó a adquirir rebaños que según las estimaciones más abultadas alcanzarían las 20.000 cabezas, disfrutando de derechos de posesión para unas 7.000 cabezas en las dehesas de la Serena de la mesa maestral de Alcántara, las más apreciadas por los ganaderos sorianos por su seguridad y moderado precio, y que por ello tendieron a quedar reservadas para los grandes propietarios hidalgos ${ }^{41}$.

Los descendientes de Gabriel de Cuenca no siguieron dedicados al negocio ganadero y sus derechos de posesión en La Serena debieron ir a parar a manos de nobles, y entre otras, aunque sólo transitoriamente, a las del conde de Águilar. Otras familias de mercaderes avecindadas en Soria consiguieron sin embargo en el transcurso del XVI acceder también a los apetecidos pastos de la mesa maestral de Alcántara, a través de la compra de rebaños con sus correspondientes derechos de posesión a familias de la nobleza ganadera, como por ejemplo la de los Ríos, que en la segunda mitad del XVI fue la principal acaparadora de estos derechos en La Serena. Pero esta penetración de ganados de hombres de negocios sorianos a los privilegiados pastos de la mesa maestral de Alcántara tuvo lugar según todos los indicios muy a finales del siglo XVI, y fue de alcance muy limitado. En concreto si atendemos al reparto del pago de hierbas del ejercicio 1598-9 observamos que aunque el número de posesioneros hombres de negocios era superior al de ganaderos hidalgos, 6 frente a 4, la balanza se inclinaba claramente a favor de los segundos por el número de cabezas de pose-

10. La escritura de ajuste de cuenras y disolución de la compañía, fechada en Cabrejas del Campo, 11-I-1600, en AHPS,PN, 286-567-22. En la compañía había entonces 8 rebaños de ovejas y 3 de carneros moruecos y borros, todo ganado trashumante.

$4 i$ Vid. nuestro libro Soria en la Baja Edad Media... pp. 162-167. Y también nuestro artículo "Grandes y pequeños ganaderos trashumantes en las sietras sorianas en el tránsito de la Edad Media a la Moderna», Revista de Historia Económica, XII, 2 (1994), pp. 354 y ss.

Hisponics, LX/2, num. $205(2000) 479-514$ 
sión disfrutado, que era de 74.912 en el caso de los hidalgos, frente a 22.376 en el de los hombres de negocios ${ }^{42}$. Con todo algunos de estos ganaderos mercaderes consiguieron alcanzar notables cotas de prosperidad en los últimos años del siglo XVI, y el ejemplo más notable nos lo ofrece de nuevo el polifacético Domingo del Aguila, quien en 1592 obtuvo de su rebaño trashumante una cantidad de corderos superior incluso a la del propio regidor Antonio López de Río, aunque muy por debajo de la del también regidor Alonso de Río ${ }^{43}$.

La inclinación de algunos de estos mercaderes sorianos hacia la inversión en compra y explotación de ganados, preferentemente trashumantes, pero en el caso de algunos también estantes o trasterminantes ${ }^{44}$, no estuvo sin embargo exclusivamente motivada por su vinculación con el comercio lanero, que les despertase el deseo de disponer de lana propia para la venta, sino que para bastantes de ellos otro factor determinante fue su constante participación en negocios de arrendamientos de las carnicerías de la ciudad de Soria.

\section{DIVERSIFICACIÓN DE LAS INVERSIONES}

Si bien es cierto que el comercio lanero representó la actividad económica mercantil de mayor envergadura en Soria durante el siglo XVI, y que ninguna fortuna entre las familias de mercaderes se forjó al margen de esta actividad, tampoco ninguno de los hombres de negocios sorianos de relieve se especializó exclusivamente en el trato de las lanas, sino que fue norma sin excepción que todos ellos diversificasen de forma extraordinaria sus inversiones, participando prácticamente en todas las ramas de la actividad mercantil y financiera. Entrar

42 Los datos del reparto de las hierbas de la mesa maestral de Alcántara correspondientes al ejercicio 1598-9 en AHPS, PN, 139-481, 5-IX-1599. Hemos identificado como ganaderos hidalgos a Alonso de Río, Antonio López de Río, Francisco González de Río, Rodrigo de Salcedo y Diego de Medrano. Como hombres de negocios a Sebastián de Salcedo, yerno de Ana de Lumbreras; Juan de Barnuevo, platero y Francisco de Barnuevo, Domingo del Aguila, Pedro de Santa Cruz y Lucas Álvarez.

43 Los datos de 1592 los ofrece en cuadro DíEz SANZ, E.: op. cit. pp. 351-2. La lista sin embargo es incompleta, advirtiéndose la ausencia de figuras significativas, como la del alférez Francisco López de Río, quien debía ser entonces el máximo propietario de ganados de Soria. Los tres mayores productores de corderos uextremeños" que aparecen en el cuadro son el regidor Alonso de Río con 7.520 , Domingo del Águila con 2.160 y el regidor Antonio López de Río con 2.100 .

14. Por ejemplo Diego Ruiz consta que tuvo un rebaño estante porque en 1572 su viuda vendió 82 arrobas de lana churra del ganado de su difunto marido. AHPS, PN, 79-178. En el padrón de producción de corderos de 1592 reproducido pro DíEz SANZ E.: figuran varios hombres de negocios como productores de corderos churros, como Pedro de Santa Cruz o Crisróbal de Viguera, además de orros varios que aparecen como tales con motivo de haber sido arrendadores de la carnicería, en concreto Ana de Lumbreras y su yerno Sebastián de Salcedo, Domingo del Águila y Lucas Âlvarez. Un caso singular es el de los hermanos Francisco y Juan de Barnuevo, quienes declararon bastantes corderos churros trashumantes, paradójicamente más que corderos extremeños. 
a aportar datos para probar esta aseveración podría resultar sin embargo excesivamente prolijo, y por ello vamos a limitarnos simplemente a comentar algunos casos individuales muy significativos, que servirán para ilustrar esta compleja realidad.

\section{Domingo del Águila}

Una de las figuras más atrayentes de cuantas conformaron la comunidad soriana de hombres de negocios de la segunda mitad del siglo XVI es la de Domingo del Águila, individuo que presumimos que debió nacer hacia 1550,y que desartolló una extraordinaria actividad, dentro y fuera de la ciudad, tratando de sacar provecho económico de los más diversos negocios.

Comenzamos a tener noticias de sus actividades en 1566, cuando ya aparece suscribiendo contratos de reventa de lanas churras a fabricantes de paños de Lumbreras de Cameros conjuntamente con su suegro Gregorio de Molina ${ }^{45}$. Este negocio de la compra de lana churra a campesinos del ámbito soriano y posterior reventa de la misma a fabricantes de las villas y aldeas cameranas, lo continuó realizando, primero junto con su suegro y más tarde él solo, en las décadas siguientes, aprovechando la disponibilidad de capital que le permitía adelantar dinero a los propietarios de ganado churro varios meses antes de la entrega de las lanas, y una vez recibidas éstas revenderlas a pago aplazado a los fabricantes cameranos ${ }^{46}$.

El comercio de lana churra representaba sin embargo un negocio menor, que generaba limitados beneficios, porque las cantidades de lana con las que se debía trabajar tanto en los contratos de compra como en los de reventa eran muy pequeñas, y los márgenes de beneficio en las operaciones también muy reducidos. Por esta razón los tratantes que se limitaban a negociar con este tipo de lanas eran siempre individuos que no llegaban a alcanzar la categoría de auténticos mercaderes, sino que con frecuencia ejercían profesiones como las de boticario, oculista, cirujano o barbero, u otras de carácter más marcadamente artesanal como la de platero, y se aventuraban en los negocios de compraventa de lana churra para incrementar sus ingresos, proporcionando inversión al pequeño excedente de capital de que disponían. Domingo del Águila era un individuo con mayores ambiciones y por ello pronto dio el salto al más lucrativo negocio de la lana "extremeña", que era como se llamaba la procedente del esquileo de los ganados trashumantes.

45 Contrato de teventa de lana churra a un vecino de Lumbreras en AHPS, PN, 76-172. Debermos presumir que casaría a edad muy temprana, pues para 1566 no parece probable que sobrepasase los 20 años.

46 Vid. nuestro artículo «El comercio de las lanas churras...» 
Los primeros pasos en este negocio parece sin embargo que los dio Domingo del Aguila en calidad de factor o agente al servicio de mercaderes foráneos. Así por ejemplo en 1581 lo encontramos actuando en nombre de la compañía de Francisco y Bernardo Nebrese, de la que formaba parte también Hilario Bonafont, que terminaría convirtiéndose en su socio, según ya hemos visto. En 1583 aún sigue trabajando al servicio de esta compañía, pero al mismo tiempo aparece realizando compras de lanas en nombre del mercader de Vitoria Fernando de Zárate, a quien continuó sirviendo como agente varios años más. Y más adelante, por fin, también lo encontramos actuando al servicio de mercaderes flamencos residentes en Bilbao y Medina del Campo, y de otros mercaderes de Vitoria, como Juan de Salinas ${ }^{47}$.

Las tareas que desempeñaba en Soria Domingo del Águila al servicio de estos mercaderes foráneos eran múltiples, destacando las de concertación de contratos de obligación con ganaderos vendedores de lanas, recibo de estas mismas lanas y organización del proceso de su lavado y ensacado. Y de ahí que llegase a ser propietario de uno de los tres lavaderos que funcionaban en la ciudad de Soria a orillas del Duero a fines del siglo XVI y comienzos del XVII ${ }^{48}$. Pero en la década de 1590 debió dar ya el salto definitivo que le convirtió de simple agente al servicio de mercaderes foráneos en auténtico mercader independiente, capaz de aventurarse en empresas propias de exportación. Y así lo demuestra el evidente cambio de sentido de su relación con Hilario Bonafont, a quien había comenzado sirviendo como agente, y del que terminó convirtiéndose en socio durante los últimos años de su vida, para después de su muerte casar incluso con su viuda.

Su actividad como mercader de lanas churras y extremeñas puso en contacto muy pronto también a Domingo del Águila con el mundo de la fabricación de paños, actividad económica que en la región soriana se podría considerar como la segunda en importancia después de la de producción lanera, al menos por sus repercusiones en el terreno de los intercambios, ya que en lo que afecta a asegurar la subsistencia de la mayoría de la población no cabe duda que ambas actividades ocupaban un lugar muy secundario frente a la agricultura. Aunque la historia de la pañería soriana y camerana en el siglo XVI se encuen-

47 Referencias a compras de lanas efectuadas por Domingo del Águila en 1583 a favor de Fernando de Zárate, por un lado, y de la compañía Bonafont-Nebrese por otro en AHPS, PN, 74-166. Actuaciones en 1585 en nombre de Fernando de Zarate y Cristóbal de Soran, vecinos de Vitoria, Ibid. 178-370. En 1586 en nombte de los mismos, Ibid. 63-144, fol. 492. Actuaciones en 1590 en nombre de flamencos de Valladolid y Bilbao, de un lado, y de Juan de Salinas, vecino de Vitoria, de otro, Ibid. 241-483.

48 En 5-I-1599 unos sogueros de Soria se obligan a entregar a Domingo del Águila en su lavadero 12 piezas de parella AHPS, PN, 271-545-20. Los propietarios de los otros dos lavaderos en esta época eran Juan García de Tardajos y el judeoconverso portugués Simón Fernández de Oporto.

Hispania, LX/2, núm. 205 (2000) 479-514 
tra prácticamente todavía sin explorar ${ }^{49}$, hemos podido constatar a través de la documentación consultada que la ciudad de Soria fue en el siglo XVI un activo centro de producción de paños de lana, y que al mismo tiempo en las aldeas serranas de su jurisdicción y sobre todo de las jurisdicciones señoriales situadas más al norte, como por ejemplo las de Yanguas y San Pedro Mantique, numerosos campesinos trabajaron en la fabricación de paños, generalmente de peor calidad, que tenían el mercado rural como principal destinatario. Los mercaderes no se mantuvieron al margen de esta actividad, sino que por el contrario en muchos casos fueron sus principales promotores, y trataron de sacar provecho de ella por todos los medios. En concreto Domingo del Águila estuvo relacionado con la fabricación de paños en los talleres rurales de Cameros y Tierra de Yanguas como proveedor de lanas churras, y también de lanas extremeñas procedentes de los desechos de sus lavaderos, que eran preferentemente consumidas en estos talleres, aunque excepcionalmente también en talleres urbanos, como los de Soria o Burgos ${ }^{50}$. Pero su vinculación con la fabricación de paños en la propia ciudad de Soria fue más intensa y estrecha, ya que no limitó a la venta de materia prima, sino que parece que también tuvo su propio obrador en el que personal asalariado tejería para él paños. Y consta que se concertó a su vez con tejedores autónomos que le tejían paños a un precio preestablecido, a los que adelantaba dinero a cambio de que se comprometiesen a tejer sólo para él durante un cierto tiempos1.

Por otra parte, además de la lana, Domingo del Águila proporcionaba a los artesanos pañeros otras materias primas, como por ejemplo los productos colorantes empleados por los tintoreros, preferentemente añil y pastel, que en ocasiones él redistribuyó en el ámbito soriano como encomendero de mercaderes foráneos ${ }^{52}$.

49 Sólo para algunas comarcas de esta amplia región serrana, que hoy se reparten las provincias de Soria, Burgos y Logroño, aporta datos la obra de BrumonT, F.: Paysans de Vieille Castille aux XVIle et XVIle. siècles, Casa de Velázquez, Madrid, 1993, pp. 133 y ss. Sobre el caso concreto de la ciudad de Soria hemos tratado someramente en $*$ Desarrollo de la industria pañera en Soria en el siglo XVI" Celiberia, 87-88 (1994), pp. 105-30.

so Destaca un contraco de venta de 246 arrobas de lana de tercero y cuarto efectuada por Domingo del Águila a un pañero, vecino de Burgos, en 24-[X-1590, procedente del lavadero que ese año había realizado en Soria para unos mercaderes flamencos. Este y otros contratos de venta de despojos de lavadero efectuados por Domingo del Águila en AHPS, PN, 241-483. También en 74-166.

"En 2-XII-1583 se concierta con Martín de Río, tejedor de Soria, que éste le tejerá en su casa en unos telares todos los paños que pudiere, sin entrometer paños de ningún otro dueño, durante los años 1583 y 1584. Se le pagará por el tejerlos: Los dieciochenos y catorcenos, así palmillas, mezclas y frailengos, a 14 reales. Los veintidosenos a 25 reales. $Y$ los contrayes a 4 ducados (44 reales). Le adelanta 132 reales. Vid. AHPS, PN, 74-166.

52 En 1570 manifiesta que le van a traer a Soria varios productos en encomienda, sobre todo añil y pastel. Por ello llega a un acuerdo con el arrendador del peso y correduría para pagar $10 \mathrm{mrs}$. por cada 1.000 del valor de estos productos. La escritura de concierto en AHPS, PN, 77-174-64.

Hespania, IX/2, nim. 205 (2000) 479-514 
El necesario complemento a las actividades de comercio lanero y fabricación de paños era en esta época sin duda la compraventa de tejidos, por múltiples razones. En primer lugar porque había que dar salida a la producción pañera propia y de los fabricantes a los que se había adelantado materia prima o dinero, pero en segundo lugar también porque con frecuencia las lanas extremeñas eran vendidas a mercaderes foráneos que a cambio entregaban tejidos de importación y productos de mercería, que luego había que proceder a revender al detalle $o$ a intermediarios con tienda propia. El análisis de la trayectoria profesional de Domingo del Águila una vez más nos ofrece múltiples ejemplos que ilustran estas prácticas, porque consta que fue socio de varias compañías mercantiles, dedicadas al trato en paños, sedas y mercería, en las que otros vecinos de la ciudad de Soria, en varios casos parientes suyos, invirtieron elevadas cantidades de dinero, para que él negociase con ellas en el trato de esos productos ${ }^{53}$. A su vez en los protocolos notariales sorianos se pueden localizar varios contratos de venta al fiado de tejidos y productos de mercería por Domingo del Águila a intermediarios avecindados en Soria, por virtud de los cuales él adelantaba la mercancía y el comprador se comprometía a pagársela al cabo de varios meses ${ }^{\text {sa }}$. La documentación consultada hasta el momento no nos ha permitido determinar sin embargo en qué proporción estos tejidos y productos de mercería de importación fueton adquiridos por Domingo del Aguila a trueque por lanas, o tuvo que abastecerse de ellos en las ferias de Medina del Campo u otras, como era el procedimiento más habitual en la época.

Sin duda la presencia de Domingo del Águila en las ferias de Medina del Campo debió ser muy intensa, y aún más contribuirían a intensificarla sus relaciones con Hilario Bonafont, avecindado en esta villa castellana, a la que fi-

33 Domingo del Águila tuvo una compañía para el trato en mercería, y en otros negocios, con su suegro Gregorio de Molina. Un contrato que ilustra las actividades de esta compañía es el de obligación de Jorge de Beteta, alcaide de la fortaleza de Soria, para pagar a ambos 467 reales por muy diversos tejidos de importación que les había comprado. Vid. AHPS, PN, 15-39-86, Soria, 2II-1566. Después de muerto Gregorio de Molina renovó la compañia con su suegణa Luisa Núñez en 2-I-1581, haciendo constar que el dinero entonces invertido ascendía a 2.100 ducados (787.500 mrs.), de los cuales 1.100 correspondían a Luisa y 1.000 a Domingo, a pesar de lo cual los beneficios se repartirían en adelante entre ambos por mitad. Vid. AHPS, PN, 178-370-36. Por su parte en 1594 Alonso de Molina, vecino de Soria, le entregó 600.000 mrs. para que los invirtiese a pérdida o ganancia en sus tratos de paños, sedas y lanas. Vid. AHPS, PN, 241-483, Soria, 15-IX-1594.

${ }_{44}$ En 8-III-1583 Francisco de Ochavartía, vecino de Soria, se obliga a pagar a Domingo del Águila, 37.464 mrs. por 892 varas de lino, escopa y beatillas recias y delgadas, a $42 \mathrm{mrs}$. la vara. AHPS, PN, 74-166. A los pocos días, el 7 de abril, este mismo Francisco de Ochavarría vendió a otro vecino de Soria, también al fiado, 116 varas de las que él había comprado a Domingo del Águila, a un precio en este caso más elevado, que superaba los $50 \mathrm{mrs}$. por vara. Ibid. 1-IV-1583.Los contratos de obligación por ventas de paños efectuadas por Domingo del Águila son muy numerosos, y requerirían un análisis muy pormenorizado para determinar en qué casos se trataba de tejidos fabricados en Soria, y en qué casos se trataba de tejidos castellanos comprados fuera, en Segovia o en Cameros por ejemplo.

Hippania, LX/2, núm. 205 (2000) 479-514 
nalmente terminó trasladando su residencia el soriano tras su matrimonio con la viuda de este francés asentado en Castilla. Por ello nuestro polifacético mercader también nos aparece involucrado en la comercialización de productos de muy variada índole que eran importados al reino de Castilla y se redistribuían por todo él a partir de las ferias de Medina, entre otras. Se trataba en su mayoría de productos de lujo, entre los que las especias ocupaban un lugar preferente. En la venta al detalle de estas especias Domingo del Águila, a juzgar por la documentación hasta ahora consultada, nos aparece sin embargo menos activo que otros mercaderes sorianos, que poseían sus propias tiendas de «especiería y bonería». Pero sí que hemos al menos constatado su actividad como vendedor de otro producto muy vinculado a las especias, la cera, que era consumida en gran cantidad en la época para los oficios litúrgicos 55 . Otro producto por fin que también en aquellos momentos se podía considerar como «de lujo», y con el que negoció Domingo del Águila fue el libro, y sobre todo el papel, que precisamente fue el producto con el que comenzaron a hacer su fortuna los Nebrese, los tantas veces citados socios de Hilario Bonafont ${ }^{56}$.

La ciudad de Soria, a pesar de su limitado potencial demográfico, representaba ciertamente un buen mercado para la colocación de tejidos de importación y otras mercancías de lujo, porque no disponía de una industria textil especializada en la fabricación de paños de calidad y contaba con bastantes familias con buen poder adquisitivo, avecindadas tanto en la propia ciudad como en los pueblos de su entorno, gracias a la prosperidad que en el siglo XVI trajo consigo la expansión de la ganadería trashumante y de la exportación lanera. No obstante, se advierte que las familias con mayor capacidad adquisitiva no recurrían exclusivamente a los mercaderes sorianos para abastecerse de tejidos y productos de lujo, sino que con frecuencia los adquirían directamente en las ferias de Medina del Campo, a través de sus factores allí enviados para la gestión de la venta de su lanas y otros negocios, cuando no en las tiendas de mercaderes de Valladolid, Zaragoza o Madrid, en este último caso sobre todo en el siglo XVII ${ }^{57}$.

3s Vid. entre otros el contrato de obligación de dos vecinos de Gallinero, que pagarán 167 reales a Domingo del Águila por 51,5 libras de cera, a 3,25 reales la libra. AHPS, PN, 74-166, Soria, 13-I-1584.

56 En 1584 vende junto con Hilario Bonafont 334 rezmas de papel a Juan Nieto, librero de Soria. AHPS, PN, 74-166, Soria 25-IX-1584. Prueba una cierta relación con el comercio del libro el hecho de que un mercader francés vendedor de libros, procedente de París, que cayó enfermo en Soria y redactó allí su testamento en 1599 , nombró como su testamentario a Dorningo del Águila. AHPS, PN, 259-528-281.

57 Vid. por ejemplo el contrato de obligación de D. Miguel de Luna y Doña Catalina Bravo y Río, su mujer, miembro de la familia de ganaderos de mayor fortuna en Soria durante el siglo XVI, por el que ambos se comprometen a pagar a Jerónimo Salvate, mercader de Zaragoza, $151.810 \mathrm{mrs}$. por mercancias que compraron en su tienda. AHPS, PN, 64-145, Soria 1-X-1562.

Hispania, $\mathrm{CX} / 2$, núm. $205(2000) 479-514$ 
Sobre la importancia de Domingo del Águila como propietario de ganado trashumante, que pastaba en invierno en las dehesas de La Serena, ya hemos hablado, y aquí simplemente interesa añadir que además fue con frecuencia arrendador de las carnicerías de la ciudad de Soria, al igual que su yerno Martín de Barnuevo. Su participación en negocios de arrendamiento de rentas eclesiásticas, de la hacienda regia y de la hacienda concejil está por otra parte también ampliamente constatada, advirtiéndose que este hecho resulta perfectamente explicable si se tiene en cuenta que muchas de estas rentas se cobraban en especie, sobre todo cereal, corderos y lana, y que él estaba interesado en el comercio especulativo de estos productos, sobre todo del último. En otros casos su intervención en estos negocios de arrendamiento estaba sin embargo justificada por su mayor familiaridad con el negocio al que se le aplicaba el gravamen fiscal artendado. $\mathrm{Y}$ así ocurría con el arrendamiento del alcabala de las lanas, uno de los tributos de mayor rendimiento con que contaba el concejo de Soria para cumplir con el encabezamiento de alcabalas concertado con la hacienda regia, pero que a su vez plateaba enormes dificultades de cobro, a las que podían hacer frente mejor quienes estaban familiarizados con el comercio de este producto.

\section{Juan García de Tardajos}

Este mercader, que compartió con Domingo del Águila el protagonismo en la exportación de lanas desde Soria hacia Italia y Francia a fines del siglo XVI y principios del siglo XVII, y murió en 1612, pertenecía a una familia que, además de dedicarse al comercio, fue quizás una de las principales promotoras de la fabricación de paños en Soria durante el siglo XVI ${ }^{58}$. El en concreto formó una compañía con su padre para la fabricación de paños y el comercio de sedas

\footnotetext{
S8 Avanzamos algunos datos en nuestro art. «Desarrollo de la industria pañera...» Interesa hacer constar que Francisca García, tía de Juan García de Tardajos, estuvo casada con Maceo Sanz, un empresario del textil al que nos referimos en art.cit., la cual después de enviudar siguió al frente de negocios de fabricación y venta de paños, a pesar de que consta que no sabía escribir. Su sobrino Juan García de Tardajos fue su heredero. Vid. AHPS, PN, 93-208-6. Contrato de transporte a Zamora de paños de Francisca García, de 24-XII-1567, en AHPS, PN, 15-39-184. Contratos de venta de paños por Francisca García y Sebastián García, compañía, de los años 1587 a 1590 en AHPS, PN, 144-301. De gran incerés también para conocer los negocios de Francisca García resultan las cuentas de la compañía que había tenido con Julián García desde 29-XII-1593, que se cerraron el 30-I-1595. Julián García, que era el socio que administraba la compañía, compraba adelantadas lanas churras, tomaba a renta diezmos, compraba colorantes, tierra de Magán para las labores del batán y otras varias mexcancías. En contrapartida vendía muchos paños en feria de Mondéjar y, casi siempre al fiado, a campesinos de aldeas de la Tierra de Soria. También vendía cordobanes. Vid. AHPS, PN, 201-413-12. Francisca García conseguía poner a su servicio a artesanos, prestándoles dinero. Un ejemplo nos lo proporciona el caso de Andrés García, cardador, quien el 24-V-1565 se comprometió a cardar en la casa y obrador de Francisca hasta que le hubiese devuelto los 53 reales que le había prestado, descontándole de su salario un real cada semana. Vid. AHPS, PN, 15-38-195.
}

Hispania, I.X/2, núm. 205 (2000) 479-514 
y otros productos, constatándose por multitud de contratos de obligación conservados en los protocolos notariales sorianos que su actividad de vendedores de paños, tanto de fabricación propia como importados, fue notable, y que parte de los paños fabricados los exportaron fuera del ámbito geográfico soriano ${ }^{59}$. Además su interés por esta actividad se tradujo en la adquisición de varias instalaciones de infraestructura, que fueron al menos un lavadero y varios tintes, a orillas del Duero. Juan García de Tardajos no llegó a ser propietario de batanes, escasos y en su totalidad en manos de instituciones eclesiásticas y familias de la oligarquía noble, pero al menos consiguió tener a su disposición alguno, tomándolo a renta de su propietario, para luego a su vez ceder el usufructo a oficiales bataneros que se comprometiesen a aderezarle todos sus paños ${ }^{60}$.

La venta de paños de importación y otros productos varios de mercería por parte de Juan García de Tardajos está también ampliamente documentada, constatándose que unas veces los vendía él directamente a los consumidores o a pequeños artesanos ${ }^{61}$, aunque sobre todo destacaba como tratante al por mayor que abastecía a mercaderes intermediarios o simples tenderos ${ }^{62}$. En su familia por lo demás la dedicación a esta actividad económica gozaba ya de larga tradición, puesto que su padre Juan García de Tardajos y su abuela Juana Morales habían tenido una compañía de tienda de paños y sedas ${ }^{63}$, y esta última en 1568 había invertido $375.000 \mathrm{mrs}$. en una compañía con su pariente Pedro Hernández Izquierdo para el trato en mercería, que en 4 años le reportaron un beneficio de 150.000 mrs. ${ }^{64}$.

En el trato de lanas Juan García de Tardajos, siguiendo y ampliando la tradición familiar, participó en todas sus facetas, según ya hemos ido demostrando, y otra rama mercantil en la que se mostró igualmente activo fue la de

59 Vid. cuenta de paños que llevaron unos vecinos de Sevilla de Juan García de Tardajos en 1573 en AHPS, PN, $17-42$.

to Vid. contrato de subarriendo de los batanes de Chavaler, propiedad del bachiller Gutiérrez, por Juan García de Tardajos a Pedro Jiménez, batanero, en AHPS, PN, 15-39-269, Soria 2-XI1566.Vid. también nuestra artículo «Desarrollo de la industria...» pp. 114 y ss.

61 Varias ventas de III-1598 de oro fino de Milán a bordadores en AHPS, PN, 200-409.

62 Singular interés ofrece para conocer esta faceta de sus actividades un contrato de obligación que firmó el 12-III-1598 con el mercader Baltasar Romero, vecino de Soria, por el que éste se comprometía a pagarle en seis plazos 1.102.448 mrs. por razón del resto del precio de una larga serie de mercancías que le había comprado, entre las que figuran aparte de tejidos de fabricación soriana y segoviana, otros muchos productos de importación como oro fino de Milán para bordados, pamelotes de Nápoles y Venecia, terciopelos, rasos, damascos, etc. Vid. AHPS, PN, 200-409. Este Baltasar Romero era un intermediario, que al parecer tenía arrendada una tienda de Juan García de Tardajos en Soria. Lo encontramos por ejemplo vendiendo tejidos al señor de Hinojosa de la Sierra en 1602. Vid. AHPS, PN, 96-213-80.

63 Consta por escritura de 3-IV-1549, en AHPS, PN, 23-53-43.

64 Según consta en escritura fechada en Soria, 18.V-1572, en AHPS, PN, 79-178.

Hispania, 1X/2, núm, 205 (2000) 479-514 
compraventa de colorantes ${ }^{65}$. Su participación en arrendamientos de diezmos le permitió por su parte con frecuencia disponer de importantes cantidades de cereal para la comercialización, y por ello no es inhabitual encontrarle involucrado en operaciones de venta al fiado de este producto a campesinos necesitados, aunque también en otras de préstamo en dinero reintegrable en cereal.

Otro terreno en el que Juan García de Tardajos desarrolló una notable actividad fue el de las finanzas. En concreto nos consta que estuvo muy relacionado con banqueros madrileños, por lo que alguno de los grandes señores de ganados sorianos recurrieron a él para cobrar las cantidades que se les debían por la venta de sus lanas, como fue el caso del alférez Francisco López de Río en los primeros años de la década de $1590^{6}$. En contrapartida financieros asentados en Madrid le encargaban a él el cobro de determinadas partidas, como por ejemplo los 400 ducados que en 1598 recibió de un canónigo de Osma para el italiano Nuncio Paravicino ${ }^{67}$.

Sus propias empresas de exportación de lanas a Italia le debieron poner en contacto con este mundo de las altas finanzas, cada vez más centrado en torno a Madrid en esta época, pero también debió influir su frecuente elección como recaudador del servicio ordinario y extraordinario de la provincia de Soria por los procuradores a Cortes de esta ciudad. Y esta familiaridad con la gestión de las rentas de la hacienda regia explica también que muchos beneficiarios de juros le encargasen a él de su recaudación, a cambio por supuesto de una comisión $^{68}$.

Y por si fuera poco Juan García de Tardajos fue también escribano desde que en 1558 , cuando todavía debía contar con muy pocos años, su padre re-

6s Al ya mencionado contrato con un mercader de Toulouse para el trueque de lanas por pastel, podemos añadit a título ilustrativo diversos contratos de venta de añil de Guatemala de 1602 y 1603 en AHPS, PN, 334-631.

66 Vid. carta de obligación de Juan García de Tardajos para pagar al alférez $2.494 .876 \mathrm{mrs}$. puestos parte en Soria y parte en Madrid, porque el alférez ha dado poder al banquero madrileño Juan Luis Vitoria para cobrar esta cantidad de Domingo del Águila e Hilario Bonafont, compradores de las lanas del alférez, y asentarla a nornbre de Juan García de Tardajos. AHPS, PN, 89-198426, Soria 3-III-1593. La carta de poder con misma fecha a Juan Luis Vitoria, Ibid. fol. 6. Otra carta de obligación semejante, tocante a $1.433 .412 \mathrm{mrs}$. procedentes de la misma obligación de venta de lanas, que ascendía a 5.361 .690 mrs. fechada en I7-II-1595 en AHPS, PN, 90-200-57. El poder a Juan Luis Vitoria y Antonio Suárez de Vitoria, con misma fecha en AHPS, PN, 89-199-9. Letra de Juan Luis Vitoria de 1595 , ordenando a Juan García de Tardajos pagar 40.000 reales al mercader burgalés Gaspar de Arlanzón, en AHPS, PN, 202-416-94. Sobre los banqueros madrileños Juan Luis Vitoria y Antonio Suárez Vitoria, que también participaron en exportaciones de lanas a Italia, aporta algunas noticias H. LAPEYRE, Simón Ruiz et les Asientos de Philippe II, París, 1953.

67 Vid. AHPS, PN, 206-424-190.

${ }_{68}$ Obligación de Juan García de Tardajos para pagar a Diego de Vinuesa Barnuevo, regidor de Soria y señor de las villas de la merindad de Solpeña, 889.999 mrs. de juros que se le debían en los partidos de Atienza y Molina. Vid. AHPS, PN, 271-545-1. 
nunció en él su escribanía del número ${ }^{69}$. En este sentido, no obstante, se limitó a sintonizar con la norma habitual en la Soria del momento, ya que entre los hombres de negocios sorianos hubo entonces una gran cantidad de escribanos, hasta el punto de que éstos y los titulados universitarios formaron el grueso de este grupo socioeconómico, pudiéndose considerar casos excepcionales los de negociantes de talla que no pertenecieron a ninguno de estos dos sectores, como le ocurrió al parecer a Domingo del Águila ${ }^{70}$.

Una actividad económica en la que sin embargo la figura de Juan García de Tardajos no despuntó fue la de cría de ganado ovino trashumante o estante, aunque hay constancia de que al menos realizó también algunas incursiones en este terreno, que debieron resultar en un relativo fracaso ${ }^{71}$.

Por supuesto ni Domingo del Águila ni Juan García de Tardajos ni ningún hombre de negocios soriano del XVI pudieron abarcar todas las gamas de actividad económica, y así por ejemplo ninguno de estos dos parece que intervino de forma significativa en un negocio de notable importancia en la Soria del momento, como era el del cuero ${ }^{72}$, a diferencia de otros colegas suyos. Cada mercader presentaba sus propios rasgos singulares, y no viene aquí al caso dar cuenta de todos y cada uno de ellos, pero en conjunto todos tuvieron en común su decidido interés por diversificar las inversiones. $\mathrm{Y}$ los datos ofrecidos sobre estos dos brillantes hombres de negocios sorianos del Siglo de Oro así lo han podido demostrar suficientemente.

\section{ESTIMACIÓN DE LAS FORTUNAS Y COMPOSICIÓN DE LOS PATRIMONIOS}

A pesar de que los hombres de negocios sorianos del siglo XVI supieron diversificar sus actividades e inversiones del modo que hemos podido comprobar, derrochando dosis de iniciativa y capacidad de trabajo, su posición dentro de la jerarquía sociopolítica urbana fue por lo general de segunda fila. De hecho este grupo no se caracterizó nunca por su homogeneidad desde el punto de vista

\footnotetext{
69 Según consta en los libros de actas del ayuntamiento de Soria, acca del 23-XII-1558. Pensamos que Juan García de Tardajos debía ser entonces muy joven, porque por referencias varias deducimos que suz padre debía cener entonces 38 años.

${ }^{70}$ La condición de acaudalados de muchos escribanos y letrados en la Soria del siglo XVI no era de hecho sólo resultado de que la burocracia fuese actividad muy rentable en la Castilla de Felipe II, como se ha sugerido, puesto que la mayoría de estos individuos debían gran parte de su fortuna a su actividad como mercaderes, financieros y promotores de la fabricación de paños. Contrastar con la tesis de Díkz SANZ, E. La Tierra de Soria... pp. 391-2.

7 Consta que antes de 1600 había comprado 990 carneros a Sebastián de Salcedo, tal vez para abastecimiento de carnicerías, de los cuales al poco se le murieron alrededor de 750 . Vid. AHPS, PN, 210-430-148. En julio de 1600 por su parte vendió un rebaño de unas 500 ovejas a un vecino de Suellacabras. AHPS, PN, 210-430-150.

72 A Domingo del Águila sólo lo hemos encontrado vinculado al negocio del cuero cuando era arrendador de carnicerías y vendía los pellejos del ganado sacrificado en las mismas a valdreseros.
} 
sociopolítico porque sus miembros no presentaban una adscripción estamental única, sino que unos pocos pertenecieron ya en su origen a los linajes de caballeros hidalgos, otros iniciaron sus carreras como miembros del Común de pecheros, y el sector más numeroso estuvo constituido por los que consiguieron la exención de impuestos gracias a títulos universitatios o a escribanías del númeto, aunque en última instancia la mayoría aspiraron a la hidalguía, y muchos la consiguieron. No cabe duda, por consiguiente, que para bastantes de ellos el éxito en los negocios fue una efectiva vía de promoción sociopolítica, que les permitió auparse por encima de la masa de los pecheros, pero salvo raras excepciones no les garantizó el acceso al más selecto grupo de la oligarquía, al que por el contrario sí que accedieron en el transcurso del siglo XVI numerosos señores de ganados procedentes de ámbitos rurales ${ }^{73}$. Sólo el caso de la familia Beltrán, que hemos analizado con detenimiento en otro lugar, contradice esta tendencia general por su tápido ascenso, que en poco tiempo les llevó al regimiento, al señorío de vasallos y a múltiples enlaces con familias de la nobleza media soriana ${ }^{74}$. Pero en contrapartida las otras familias de hombres de negocios a las que aquí nos hemos referido se mantuvieron en unas posiciones sociopolíticas mucho más modestas, porque no consiguieron amasar fortunas tan grandes como la de los Beltranes.

En efecto, al analizar la composición y valor de las fortunas de los hombres de negocios de un lado, y las de los miembros de la oligarquía de otro, podemos advertir que la distancia entre estos dos grupos no era sólo resultado de una diferencia de prestigio de sangre sino también de riqueza y fuentes de ingreso. Los datos de que disponemos para probar esta aseveración no son de momento muy numerosos ni precisos, aunque cabe abrigar la esperanza de que se puedan incrementar considerablemente a partir de la consulta de nuevas fuentes documentales, sobre todo procedentes del Archivo de la Chancillería de Valladolid.

No disponemos de datos ni estimaciones sobre el valor de la hacienda de Domingo del Águila, quien por lo demás por indicios presumimos que sufrió graves reveses financietos en los primeros años del siglo XVII, que quizás le llevaron cerca de la ruina. Sobre Juan García de Tardajos disponemos de bastantes más datos, que nos sugieren que su fortuna y la de su familia tuvieron una importancia relativamente modesta, aunque en comparación con la masa de la población soriana se trataba de un individuo sin duda rico. Un Juan García de Tardajos que en 1570 tenía 50 años, y que sin duda era el padre de nuestro personaje, según estimaciones de testigos poseía bienes por valor de unos 8.000 ducados, cantidad que quedaba muy por debajo de los 15.000 ducados en que se estimaba por estos mismos testigos la fortuna de otro destaca-

73. Vid. nuestro artículo «Caballeros y ganaderos. Evolución del perfil socioeconómico de la oligarquía soriana en los siglos XV y XVI» Hispania, 184 (1993), pp. 451-96.

74 Vid. nuestro artículo «El ascenso sociopolítico..."

Hispania, LX/2, núm. 205 (2000) 479-514 
do mercader soriano del momento, Diego Ruiz, pero muy por encima de los 3.000 ducados en que se valoraba la de Pedro de Santa Cruz y Francisco de Neila ${ }^{75}$. Entre esta fecha y la de su muerte, en 1597, este individuo incrementaría notablemente su fortuna, ya que su hijo Juan García de Tardajos, que redactó su testamento en 1612, reconoció entonces que había heredado de su padre en concepto de bienes libres fuera del mayorazgo más de 8.000 ducados, y más adelante de su sobrina María García de Vera, hija de su hermano Jerónimo, bienes troncales que ascendieron a 1.200 ducados. Este Juan García de Tardajos al heredar la fortuna de su padre ya era $\sin _{\text {in }}$ embargo un individuo bastante acomodado, puesto que según su declaración poseía 4.000 ducados al contraer matrimonio con María de Soria. Desafortunadamente desconocemos el valor de la hacienda dejada por él a su muerte en 1612, aunque según su propia declaración superaba con creces la cifra de 14.600 ducados, correspondiendo el exceso sobre esta cantidad a bienes gananciales habidos durante el matrimonio.

Sí disponemos sin embargo del inventario de bienes que poseía este individuo al morir, sin su correspondiente tasación, que es la que nos hubiera permitido conocer el valor estimado de los mismos. La identificación de los bienes nos permite, no obstante, comprobar que, a diferencia de su padre, que tenía la mayor parte de su patrimonio invertido en su negocio mercantil y de fabricación de paños ${ }^{76}$, había puesto en práctica una sistemática política de inversión de sus beneficios en bienes susceptibles de proporcionarle una renta más o menos fija, como eran las tierras y los juros ${ }^{77}$. Por contraste en el inventario están

75 Vid. AHPS, PN, 77-174-198. Estimación del «abono» de unos fiadores, en Soria 25-IX1570. Pedro de Santa Cruz fue comerciante de lanas, que trabajaba como factor al servicio de mercaderes burgaleses, como Cristóbal Cerezo. Fil valor de la hacienda del escribano Alonso Núñez, mercader exportador de lanas, fue estimado también en más de 8.000 ducados.

76 En el testamento de su padre, Juan García de Tardajos el mayor, fechado en Soria 10-VIII1592, éste manifestaba que queria aumentar el mayorazgo heredado de sus antepasados, pero que en aquel momento no disponía de bienes libres con que hacerlo porque toda su hacienda estaba invertida en la compañía que tenía con su hijo, dedicada al obraje de paños, tienda, sedas y alquiler de casas. Copia del testamento, que fue abierto a su muerte en 1597, en AHPS, PN, 206-423-294. En el testamento de Juan García de Tardajos el menor, fechado en Soria el 4-I-1612, éste manifestó que él había heredado de su padre más de 8.000 ducados, de los cuales $2.857 .243 \mathrm{mrs}$. procedían de lo que a su padre le correspondía en la compañía que ambos habían cenido. El cestamento en AHPS, PN, 342-639-160.

7 Poco antes de morir, el 4-I-1612, Juan Garcia de Tardajos recibió del tesoreto de las alcabalas de Soria $448.522 \mathrm{mrs}$. que le correspondia cobrar por seis juros situados sobre dichas rentas que había comprado a la hacienda regia para sí mismo y para sus dos hijos. Vid. AHPS, PN, 345-642533. De hecho empleó los juros y las tierras para entregar la dote a su hija y el adelanto de legítima a su hijo, según declaró en su testamento. A la primera le entregó como dote 2.123 .650 mrs.en las siguientes partidas: $1.240 .000 \mathrm{mrs}$. en un juro, $450.000 \mathrm{mrs}$. en 4 yuntas de heredad en Nomparedes, y 375.000 mrs. en dinero, plata, oro y vestidos. A su hijo le entregó como adelanto de legítirna $y$ herencia 3.284.891 mrs. en las siguientes partidas: $1.970 .680 \mathrm{mrs}$. en un juro, $768.061 \mathrm{mrs}$. en 7

Hispania, LX/2, núm. 20S (2000) 479-514 
muy poco presentes elementos que cabría esperar en la hacienda de un mercader y fabricante de paños, como podrían ser mercancías tales como lana, productos tintóreos o tejidos, o relaciones de deudas contraídas con proveedores y de cantidades adeudadas por clientes compradores. Muy probablemente este fenómeno se deba a que Juan García de Tardajos, presintiendo ya cerca el momento de la muerte, habría ido tratando de liquidar todos sus negocios para dejar a sus descendientes la hacienda lo más saneada posible. No obstante, su único hijo varón, Lucas García de Vera, no por ello se volcó de lleno al disfrute de la vida de rentista, aprovechando los juros y las tierras que le había cedido su padre, sino que por el contrario continuó siendo un activo mercader, al que encontramos sobre todo negociando con lanas, en contacto con exportadores judeoconversos portugueses ${ }^{78}$.

Un pariente de Juan García de Tardajos, el licenciado Juan García, médico, con el que realizó conjuntamente muchos negocios de contratación de lanas ${ }^{79}$, consta por estimaciones que dejó al morir en 1630 una hacienda valorada en más de 30.000 ducados (11.250.000 mrs.), si bien en su caso queda constatado que además de mercader fue un destacado propietario de ganados trashumantes $^{80}$. Por su parte a efectos de comparación podemos recordar también que otro soriano con un perfil muy parecido al del licenciado Juan García, el doctor Alonso de Santa Cruz, médico, muy activo en el negocio de préstamo usurario y compra adelantada de lanas a pequeños productores en otoño, dejó en el momento de su muerte en 1615 bienes por valor de más de 21.000 ducados $^{81}$. Otro mercader muy activo en el negocio lanero y de fabricación y venta de paños, aunque no involucrado en empresas de exportación, Hernando Ibáñez, consta por fin que al contraer matrimonio en 1606 con Clara Rodríguez de San Clemente disponía ya de un patrimonio valorado en 5.000 ducados, de los cuales 3.000 correspondían a lo que debía heredar de su difunto padre Pedro Ibánez, y 2.000 a una mejora de cuarto y quinto que ya en vida le prometió su

\footnotetext{
yuntas de heredad en Nomparedes, 112.500 mrs. en una yunta de heredad y parte de un molino en Renieblas, y 375.000 mrs. en dinero, oro, plata, ajuares y preseas. Vid. AHPS, PN, 342-639-160.

78 Fue por ejemplo factor de Jerónimo de Fonseca, según atestiguan los protocolos notariales. Siguió manteniendo el tinte y lavadero heredados de su padre hasta que en 1628 los vendió al mercader lanero soriano Bernardino Marcel por 16.500 reales. Fue el signo definitivo de la retirada de la familia García de Tardajos del mundo de los negocios. Vid. AHPS, PN, 454-794-255 y 461-802-13.

79 Numerosos contratos de obligación correspondientes al año 1595 en que aparecen ambos conjuntamente en AHPS, PN, 202-415.

go Estimación del valor de su hacienda, y apertura de su testamento en AHPS, PN, 512-886288. En el testamento hace constar que era primo de Lucas García de Vera, por lo que se deduce que debia ser sobrino de Juan García de Tardajos y María de Soria.

81 Vid. partición de bienes del doctor Santa Cruz en AHPS, PN, 351-649-350. Abundan las deudas en lana y en trigo. La importancia porcentual de los ganados es relativamente reducida, ya que sólo se registran 320 carneros, valorados a 14 reales la cabeza, y 92 machos cabríos valorados a 19 reales cabeza.
} 
madre Ana de Lumbreras, con la que realizaba la mayor parte de sus negocios en compañía ${ }^{82}$.

Pero centrándonos más en los datos de que disponemos sobre individuos fallecidos en el propio siglo XVI nos encontramos con cifras relativamente más modestas, puesto que por ejemplo el cuerpo de hacienda dejado a sus herederos por el matrimonio de Juan Núñez e Isabel García de Tardajos, tía de Juan García de Tardajos el mayor, fue valorado en 1574 en 2.760 .095 mrs. ${ }^{83}$. No obstante, este Juan Núñez no respondía al típico perfil del mercader que especulaba con mercancías al por mayor, sino que más bien presentaba las características del tendero, merceto y especiero, que compraba al fiado tejidos, productos de mercería, especias y otras mercancías de lujo en las ferias de Medina del Campo y las revendía en su tienda de la ciudad de Soria ${ }^{84}$. Sus hijos, el escribano Alonso Núñez y el licenciado Juan Núnez, por el contrario sí que se embarcaron en empresas mercantiles más ambiciosas, formando parte de compañías de exportación de lanas junto con metcaderes franceses. $Y$, aunque no disponemos de cifras precisas, presumimos que debieron alcanzar mucha mayor fortuna material, sobre todo el último, que heredó los bienes de su hermano el escribano, muerto sin descendencia, y consiguió que sus hijos enlazasen por matrimonio con familias de la oligarquía soriana y alcanzasen la condición hidalga ${ }^{85}$.

Por debajo incluso del valor de la hacienda de Juan Núñez e Isabel García de Tardajos se situaba el de la del escribano Antón Rodríguez de San Clemente, hombre de negocios de talla menor, que se mantuvo al margen de las empresas de exportación de lanas y centró su actividad sobre todo en la compra por adelantado en otoño de lanas churras, y en menor medida extremeñas, de

${ }_{82}$ Según consta por la escritura de capítulos matrimoniales, en Soria, 2-II-1606. AHPS, PN, 100-223-39.

B3 La partición de bienes en AHPS, 3522-3.

84 Así se deduce en primer lugar de varias noticias contenidas en su testamento, sobre deudas con mercaderes de Medina del Campo, y compras de mercancias al fiado efectuadas en las ferias de esta villa. Copia del zestamento en AHPS, 3522-3. En la partición de bienes figura una larga tasación de productos que había en la tienda de Soria, que incluye textiles de Rouen, Brecaña, Holanda, navales, angeos, manceles, pañuelos, algodón, beatillas, botones, especias, azúcar, etc. El conjunto de productos almacenados en la tienda fue valorado en $310.000 \mathrm{mrs}$.

8s Interesa recordar que la hacienda del escribano Alonso Núñez en 1570, antes de recibir la herencia de sus padres, fue valorada por testigos en más de 8.000 ducados. Cfr. nota 75 . El testamento del licenciado Juan Núnez de 1597 es copiado en AHN,OOMM, Pruebas de caballeros de Santiago, exp. 3721. En este expediente se proporcionan otros varios datos de interés sobre él y sus descendientes. Por ejemplo se hace constar que su hijo Alonso Núñez de Morales adquirió privilegio de hidalguía de Felipe III. Su hija, Isabel Núñez de Morales, casó con Diego Gutiérrez de Montalvo, regidor de Soria y procurador a Cortes por esta ciudad. La orientación rentista y pronobiliaria de los hijos del licenciado queda ilustrada a partir de muchos documentos de los protocolos notariales. Alonso Núñez de Morales había heredado de su padre y de su tío, el escribano Alonso Núñez, dos juros situados sobre las hierbas de la Serena, que le reportaban cada año $200.000 \mathrm{mrs}$. de renta, aparte de otros juros situados sobre las alcabalas de Soria. No consta en ningún momento que él se dedicase al comercio. 
las cuales parte revendía y otra dedicaba a la fabricación de paños, que él promovió a través de los procedimientos a los que habitualmente recurrían los mercaderes-empresarios sorianos. El valor total de su hacienda al morir en 1599 fue estimado en $1.732 .626 \mathrm{mrs}$. de los cuales $600.000 \mathrm{mrs}$. correspondían a sus casas principales en Soria, $207.400 \mathrm{mrs}$. al oficio de la escribanía del número y 255.000 mrs. a 500 arrobas de lana churra ${ }^{86}$. Se trata de la hacienda típica de un modesto hombre de negocios, en la que están muy poco presentes las tierras, aunque paradójicamente éstas abundaban mucho más en la hacienda de sus padres, si bien parece que en el reparto de la misma sus hermanos se quedaron con la mayor parte de la propiedad fundiaria, correspondiéndole a él en contrapartida suceder a su padre en la escribanía del número ${ }^{87}$.

$Y$ por fin, para ofrecer un último elemento de comparación tomado de los escalones inferiores en la jerarquía de los hombres de negocios sorianos, nos referiremos al caso del platero Pedro de Ojeda, quien al morir en 1607 dejó a sus cinco hijos una herencia estimada en $1.290 .289 \mathrm{mrs}$. Era una cantidad modesta, sobre todo para principios del XVII, pero además en su composición esta hacienda presentaba notables diferencias con respecto a las de los grandes hombres de negocios. En efecto, entre sus propiedades estaban ausentes los juros, y las viñas y tierras de labranza tenían una importancia muy pequeña, mientras que en contrapartida presentaban un valor porcentual muy superior las casas en Soria, y un elevado número de productos, sobre todo herramientas y mercancías, relacionados con su profesión de platero y con sus otros negocios. De hecho la figura de Pedro de Ojeda resulta muy interesante porque demuestra cómo la propensión a diversificar las inversiones no se dio sólo entre los grandes hombres de negocios sino que también los más humildes asumieron esta misma estrategia. Y así consta que, además de ejercer su oficio de platero, fue arrendador de diezmos eclesiásticos y de rentas concejiles como la alcabala del vino, trabajó con colmenas para comercializar la cera, crió palomas, fue algún año abastecedor de carnicerías y propietario ocasionalmente de novillos que criaba en la dehesa de Valonsadero para su posterior venta, tuvo tienda de mercería y ferretería, y por supuesto también se dedicó a la compraventa de lanas churras, el negocio más socorrido por los sorianos de origen relativamente humilde que deseaban prosperar en el mundo del comercio. Y con el poco dineto que le sobraba también se dedicaba a realizar pequeños préstamos, y pequeñas inversiones, como cuando entregó a su primo Francisco García, valdre-

86 Tasación de los bienes en AHPS, PN, 102-226-116.

87 El reparto de los bienes de Gonzalo de Soria, escribano del número, y Juana Rodríguez de San Clemente en 1561 entre sus hijos licenciado Soria de San Clemente, licenciado Gregorio de Soria, cura, bachiller Francisco de Soria, cura, y Andrés Rodríguez de San Clemente, escribano, en AHPS, PN, 87195. Las casas en Soria representaban el 27,11\% del valor total de la hacienda (estimado en 1.090 .797 mrs.), y las viñas y tierras de labranza el 53,69\%. Se hace constar que el único de los hijos sin titulación universitaria, Antón, había sido mejorado en el oficio de escribanía del número. 
sero, 2.000 reales para que los emplease en su viaje a Sevilla, probablemente para adquirir cueros sevillanos, muy demandados en el mercado soriano ${ }^{88}$.

El análisis comparado de los ejemplos propuestos y de otros varios conocidos a través de la documentación consultada demuestra que entre los hombres de negocios sorianos había establecida una clara jerarquía de fortunas, y que sólo los que consiguieron participar en el negocio lanero en sus fases más lucrativas, es decir, en la de reventa a mercaderes exportadores o en la de la propia exportación, amasaron fortunas de cierta importancia. Si tomamos como elemento de comparación las haciendas de los más preclaros representantes de la oligarquía noble soriana del XVI, advertimos sin embargo que incluso los mercaderes más acaudalados estaban enormemente distanciados en cuanto a nivel de riqueza de éstos, con la sola excepción quizás de los Beltranes, que de mercaderes laneros pasaron rápidamente a convertirse en señores de vasallos y propietarios de grandes extensiones de tierra ${ }^{89}$. Todavía queda mucho por averiguar sobre los niveles de fortuna de los principales representantes de la oligarquía soriana del siglo XVI, pero a título de simple ilustración podemos recordar que diversos testigos estimaron en 1594 el valor de la hacienda del regidor Francisco López de Río en 400.000 ducados, el de la de su yerno, el también regidor Antonio López de Río en 100.000 ducados, y el de la de Diego de Vinuesa en 200.000 , situándose en un nivel más modesto, aunque siempre por encima de las cifras habituales entre los hombres de negocios, los regidores Juan de Torres con 80.000 ducados y Alonso de Río con $50.000{ }^{90}$. Por supuesto estas cifras hay que tomarlas con precaución, ya que se basan en estimaciones contenidas en declaraciones de testigos, pero otras fuentes más fiables y precisas también nos confirman en la impresión de que los regidores sorianos, sobre todo los que poseían rebaños de ganado trashumante, eran notablemente más ricos que sus conciudadanos mercaderes. $\mathrm{Y}$ así por ejemplo podemos recordar que el conjunto de bienes libres, no incluidos en mayorazgo, que legaron a sus herederos el regidor Antón de Río y Ana Bravo, su mujer, fue tasado en 1560 en $58.857 .521 \mathrm{mrs}$. líquidos a repartir's1.

\section{CONCLusión}

El grupo constituido por personas que se dedicaron a negocios mercantiles y financieros de más o menos envergadura en Soria durante el siglo XVI fue

\footnotetext{
88 Nos basamos en las noticias proporcionadas por el testamento de Pedro de Ojeda, memoria de deudas, e inventario de bienes del año 1604, en AHPS, PN, 98-219-17, 23 y 45.

89 Sobre su caso tratamos en extenso en «El ascenso sociopolítico..."

90 Proporciona los datos, tomados del AHPS, DíEz SANZ, E.: Soria y su Tierra ante el sistema fiscal de Felipe II, Soria, 1987.

91 Hemos consultado la tasación y reparto de la herencia de este acaudalado matrimonio en AChV, P.C. Quevedo F. 35-1.
} 
relativamente numeroso, pero en el presente trabajo nos hemos querido referir con preferencia sólo a aquéllos que por la entidad de sus empresas pueden ser calificados como auténticos hombres de negocios, en el sentido convencional del término. Hemos podido comprobar cómo éstos en su práctica totalidad fueron individuos vinculados al comercio de la lana en sus diversas facetas, pero que además se interesaron por otras múltiples actividades económicas, entre las que de forma generalizada figuró la fabricación de paños. Ciertamente no fueron muchos, y además la inmensa mayoría de ellos pertenecían a unas pocas familias, en su mayor parte de origen judeoconverso más o menos probado, que pusieton en práctica una política matrimonial de marcado carácter endogámico, que tuvo como consecuencia que casi todos los hombres de negocios sorianos de este siglo estuviesen emparentados entre sí en un grado más o menos cercano.

A pesar de su número relativamente reducido contribuyeron decisivamente a dinamizar la vida económica de la ciudad al poner en marcha múltiples empresas generadoras de puestos de trabajo, en las que, no obstante, la posición de los trabajadores era de una extrema precariedad, ya que eran muchos los que a cambio de obtener adelantos de dinero de los hombres de negocios se obligaban a trabajar para ellos durante un cierto tiempo en condiciones bastante desfavorables. Por esta vía estos hombres de negocios hicieron posible también en gran medida el auge demográfico que conoció Soria en el siglo XVI, proporcionando sustento directa o indirectamente a muchas más personas que los miembros de la oligarquía, quienes sobre todo daban trabajo a pastores, reclutados preferentemente en ámbitos rurales. Pero a pesar de ello la ciudad siguió estando dominada desde el punto de vista sociopolítico por la nobleza urbana, a la que en el transcurso del siglo XVI se fueron incorporando varias familias ganaderas, que en algunos casos se volcaron de tal manera en la administración de sus cabañas para conseguir la obtención de los máximos beneficios, que llegaron a compartir ideales con la burguesía mercantil, respecto a la cual, no obstante, siempre trataron de dejar bien marcadas las distancias. Y por ello nunca encontramos a miembros del grupo oligárquico negociando con otras lanas que no fuesen las de sus propios ganados, o poniéndose al frente de alguna empresa de fabricación y venta de paños. A este respecto el contraste con Burgos, donde muchos regidores eran mercaderes laneros, o con Segovia, donde llegaron a acceder al regimiento incluso fabricantes de paños, era evidente.

Esta situación era sin duda consecuencia, y al mismo tiempo causa, del hecho de que Soria no consiguió controlar el comercio de exportación de las lanas producidas en su entorno geográfico, ni tampoco poner en marcha una industria de fabricación de paños tan dinámica como la segoviana. Entrar a determinar por qué ocurrió así es algo que excede las pretensiones del presente trabajo, centrado preferentemente en el análisis descriptivo de un grupo socioprofesional. Pero en cualquier caso creemos haber proporcionado suficientes datos como para probat que el contraste con Burgos o Segovia no debe ser llevado demasiado lejos, puesto que si bien es cierto que Soria no llegó a ponerse 
a la altura de ninguna de estas dos ciudades, ni como lugar de concentración de acaudalados mercaderes exportadores de lana, ni como centro de desarrollo de una dinámica industria pañera, también se puede constatar la presencia en esta ciudad a lo largo de todo el siglo XVI de emprendedores hombres de negocios, dotados de gran capacidad de iniciativa, que combinaron las dos facetas de comerciantes de lana y fabricantes de paños, y que contribuyeron decisivamente a dinamizar la vida económica urbana, aunque no llegasen a acceder al selecto grupo de la oligarquía. 